\title{
əNAO Influence on the MJO and its Prediction Skill in the Subseasonal-to-Seasonal Prediction Models
}

\author{
Hai Lin, ${ }^{a}$ Zhiyong Huang, ${ }^{\mathrm{b}}$ Harry Hendon, ${ }^{\mathrm{c}}$ ANd Gilbert Brunet ${ }^{\mathrm{c}}$ \\ ${ }^{a}$ Recherche en prévision numérique, Environment and Climate Change Canada, Dorval, Québec, Canada \\ ${ }^{\mathrm{b}}$ Canadian Centre for Meteorological and Environmental Prediction, Environment and \\ Climate Change Canada, Dorval, Québec, Canada \\ ${ }^{\mathrm{c}}$ Bureau of Meteorology, Melbourne, Victoria, Australia
}

(Manuscript received 22 February 2021, in final form 27 August 2021)

\begin{abstract}
Based on the database of the Subseasonal to Seasonal (S2S) Prediction project of the World Weather Research Programme (WWRP)/World Climate Research Programme (WCRP), the influence of the North Atlantic Oscillation (NAO) on the Madden-Julian oscillation (MJO) and its forecast skill is investigated. It is found that most models can capture the MJO phase changes following positive and negative NAO events. About 20 days after initializing with a positive (negative) NAO, the forecast MJO appears most frequently in phase 7 (3), which corresponds to reduced (enhanced) convection in the tropical Indian Ocean and enhanced (suppressed) convection in the western Pacific. In most S2S models the MJO prediction skill is dependent on the NAO amplitude and phase in the initial condition. A strong NAO leads to a better MJO forecast skill than a weak NAO. The MJO skill tends to be higher when the forecast starts from a negative NAO than a positive NAO. These results indicates that there is a strong northern extratropical influence on the $\mathrm{MJO}$ and its forecast skill. It is important for numerical models to better represent the NAO influence to improve the simulation and prediction of the MJO.
\end{abstract}

SIGNIFICANCE STATEMENT: The Madden-Julian oscillation (MJO) is a prominent large-scale tropical disturbance that has a substantial global impact. Improved understanding of the MJO and its prediction are crucial for subseasonal weather prediction. Almost all current theories of the MJO consider it as a tropical phenomenon and its generation and propagation are controlled by processes within the tropics. In this study, we show that the North Atlantic Oscillation (NAO), which is a dominant mode of variability in the extratropical Northern Hemisphere, has considerable influence on the tropical circulation and convection of the MJO. Most operational S2S models are able to capture this NAO-MJO lagged connection, and their MJO prediction skill is influenced by this process.

KEYWORDS: Madden-Julian oscillation; Teleconnections; Forecast verification/skill; North Atlantic Oscillation

\section{Introduction}

The Madden-Julian oscillation (MJO) is the prominent mode of tropical variability on the subseasonal time scale, which is characterized by a planetary-scale disturbance coupled with convection propagating eastward along the equator (e.g., Madden and Julian 1971, 1994; Zhang 2005). It has been well recognized that the MJO has a tremendous impact on weather and climate not only in the tropics but also in the middle and high latitudes, and it provides an important source of predictability on subseasonal time scales (e.g., Waliser 2012; NAS 2016).

Almost all current theories of the MJO consider it as a tropical phenomenon and its generation and propagation are controlled by processes within the tropics as summarized in several recent review papers (e.g., Zhang et al. 2020; Yang et al. 2020; Jiang et al. 2020). Most of these theories emphasize interactions between moisture and convection and

¿ Denotes content that is immediately available upon publication as open access.

Corresponding author: Hai Lin, hai.lin@ec.gc.ca cloud-radiation feedbacks in the development and propagation of the MJO (e.g., Raymond 2001; Sobel and Maloney 2012, 2013; Adames and Kim 2016; Fuchs and Raymond 2017; Khairoutdinov and Emanuel 2018). However, there exists considerable influence from the extratropics on the tropics. Extratropical waves can propagate into the tropics to influence tropical convection activity on a wide range of time scales, especially on the intraseasonal time scale associated with the MJO (e.g., Liebmann and Hartmann 1984; Webster and Holton 1982; Matthews and Kiladis 1999; Hoskins and Yang 2000). Some MJO events are found to be induced by Northern Hemisphere midlatitude atmospheric variabilities (e.g., Lin et al. 2007; Ray and Zhang 2010; Vitart and Jung 2010; Hall et al. 2017).

Tropical-extratropical interactions have been found to be an important aspect for the MJO and its global teleconnections (e.g., Frederiksen and Lin 2013; Stan et al. 2017; Lin et al. 2019). Of particular interest is the interaction between the MJO and the North Atlantic Oscillation (NAO), which is the dominant mode of variability in the Northern Hemisphere (e.g., Wallace and Gutzler 1981; Barnston and Livezey 1987) and substantially influences weather and climate in a large area in Europe and North America (e.g., Hurrell et al. 2003). Through analysis of the observed data in boreal winter, Lin et al. (2009) 
investigated the lagged connection between the NAO and the $\mathrm{MJO}$ and found that a positive (negative) NAO tends to occur 10-15 days after MJO phases 2-3 (phases 6-7), where the MJO phases are defined as in Wheeler and Hendon (2004). Similar results were reported in Cassou (2008). This lagged MJONAO connection can be explained by extratropical Rossby wave propagation (e.g., Cassou 2008; Lin et al. 2010a) and can be well reproduced in dynamical models (e.g., Straus et al. 2015; Lin and Brunet 2018; Yadav et al. 2019; Shao et al. 2019). Vitart (2017) assessed the MJO teleconnection in the models that participate in the World Weather Research Programme (WWRP)/World Climate Research Programme (WCRP) subseasonal-to-seasonal prediction project (S2S; Vitart and Robertson 2018) and found that all the S2S models are able to reproduce the MJO-NAO lagged connection, although the amplitude is weaker than in the observations. Subseasonal prediction of the NAO has been found to benefit from the MJO influence (e.g., Lin et al. 2010b; Tseng et al. 2018).

In contrast to the MJO influence on the NAO, little is known about the influence of the NAO on the MJO. Lin et al. (2009) showed that there is an influence from the extratropics to the tropics (i.e., the NAO modulates the subsequent behavior of the MJO): about 20 days following a positive and negative NAO, the MJO tends to occur in phase 7 and 3, respectively. The understanding for the dynamical mechanism of this lagged NAO-MJO connection is limited. However, Lin and Brunet (2011, hereafter LB2011) showed that MJO prediction skill is higher when initialized during a strong NAO compared to a weak NAO. LB2011 was based on a single model that was an early version of the Environment and Climate Change Canada (ECCC) atmospheric model (e.g., Côté et al. 1998), which had relatively poor MJO prediction skill (Lin et al. 2008). Thus the results of LB2011 need to be revisited.

Given the important role of the MJO in subseasonal predictions, it is of substantial importance to produce accurate MJO predictions. The MJO forecast skill has been considerably improved in the past 20 years thanks to improved model representation of clouds and convection (e.g., Bechtold et al. 2008; Hirons et al. 2013), better initial conditions and advanced ensemble techniques (e.g., Neena et al. 2014). Many current dynamical models are able to produce skillful MJO predictions with a lead time longer than 20 days, with the best models approaching 30 days (e.g., Rashid et al. 2011; Kim et al. 2014; Vitart 2017; Lim et al. 2018; Pegion et al. 2019). In addition to model and initial condition quality, several factors are found to influence the MJO prediction skill. Forecasts initialized with a strong MJO in general have a higher MJO prediction skill than those starting from a weak MJO (e.g., Rashid et al. 2011; Kim et al. 2014; Lim et al. 2018). A dependence of MJO prediction skill on the initial MJO phase has also been reported, but inconsistent among models (e.g., Lin et al. 2008; Wang et al. 2014; Xiang et al. 2015; Lim et al. 2018). Atmosphere-ocean coupling is found to be important for MJO prediction (e.g., Woolnough et al. 2007; Seo et al. 2014), but it may reduce the MJO skill when the mean bias is large (Hendon 2000). Recent studies have found that the stratospheric quasi-biennial oscillation (QBO) has strong influence on the MJO (e.g., Son et al. 2017) and its prediction skill (Marshall et al. 2017; Lim et al.
2019). Predictions performed during boreal winters when the QBO is its easterly phase in the lower stratosphere in general have a better MJO prediction skill than when the QBO is in its westerly phase (e.g., Marshall et al. 2017; Lim et al. 2019). There is also evidence that midlatitude variability influence the MJO forecast skill. For example, improved MJO prediction skill is achieved when the extratropical atmosphere is realistically represented (e.g., Vitart and Jung 2010). However, what processes are responsible and how the extratropical activity influences the MJO prediction skill is unclear.

To better understand the extratropical influence on the tropical MJO, in the present study we assess the influence of the NAO on the MJO and its prediction skill in 11 available S2S models of the WWRP/WCRP S2S project. In comparison with the observations, we look at the lagged association between the NAO and the occurrence of different MJO phases in the models. How the NAO influences the tropical zonal wind at 200 and $850 \mathrm{hPa}$ as well as tropical convection is analyzed. The dependence of MJO prediction skill on the NAO amplitude and NAO phase is investigated.

The paper is organized as follows. The observational and model data analyzed and the methods are described in section 2. In section 3, the influence of the NAO on the MJO is analyzed in the S2S models comparing with the observations. The dependence of the MJO prediction skill on the NAO amplitude is analyzed in section 4 . Section 5 compares the different influence of positive and negative NAO on the MJO prediction skill. In section 6 a possible mechanism for the NAO influence on the MJO is proposed. A summary is given in section 7 .

\section{Data and methodology}

The European Centre for Medium-Range Weather Forecasts (ECMWF) interim reanalysis (ERA-Interim; Dee et al. 2011) data are used for the diagnostic analysis and model evaluation in this study. The variables used include instantaneous zonal and meridional winds at pressure levels of 200 and $850 \mathrm{hPa}$, and geopotential height at $200 \mathrm{hPa}$. Daily mean outgoing longwave radiation (OLR) (Liebmann and Smith 1996) are used to describe the tropical convective activity.

For the S2S forecast, we make use of the reforecast data from the archive database of the $\mathrm{S} 2 \mathrm{~S}$ prediction project (e.g., Vitart and Robertson 2018; Vitart et al. 2017). Retrieved from the S2S archive database are reforecast data from 11 weather/climate centers, mostly operational centers, which are the Australian Bureau of Meteorology (BOM), China Meteorological Administration (CMA), Météo-France/Centre National de Recherches Météorologiques (CNRM), ECCC, ECMWF, Hydrometeorological Centre of Russia (HMCR), Institute of Atmospheric Sciences and Climate of the National Research Council of Italy (ISAC), Japan Meteorological Agency (JMA), Korea Meteorological Administration (KMA), U.S. National Centers for Environmental Prediction (NCEP), and U.K. Met Office (UKMO) models. Listed in Table 1 are the model descriptions with resolution, hindcast period, ensemble size, and sample size information. Reforecast output variables analyzed include zonal wind at 
TABLE 1. Description of the S2S models. Strong and weak NAOs are defined when $\mid$ NAOi $\mid>1$ and $\mid$ NAOi $\mid<0.5$ in the initial condition, respectively. Positive and negative NAOs are those with NAOi $>0.5$ and NAOi $<-0.5$ in the initial condition, respectively.

\begin{tabular}{|c|c|c|c|c|c|c|c|}
\hline Forecast center & Resolution & $\begin{array}{l}\text { Reforecast } \\
\text { length }\end{array}$ & $\begin{array}{l}\text { Reforecast } \\
\text { frequency }\end{array}$ & $\begin{array}{l}\text { Ensemble } \\
\text { size }\end{array}$ & $\begin{array}{c}\text { Total } \\
\text { reforecasts }\end{array}$ & $\begin{array}{l}\text { Strong (weak) } \\
\text { NAO events }\end{array}$ & $\begin{array}{c}\text { Positive (negative) } \\
\text { NAO events }\end{array}$ \\
\hline $\mathrm{BOM}$ & T47 L17 & 1981-2013 & 6 per month & 33 & 990 & $234(430)$ & $376(184)$ \\
\hline CMA & T106 L40 & 1994-2014 & 6 per month & 4 & 630 & $148(278)$ & $225(127)$ \\
\hline CNRM & T255 L91 & 1993-2014 & 4 per month & 15 & 440 & 112 (194) & $169(77)$ \\
\hline ECCC & $0.45^{\circ} \times 0.45^{\circ} \mathrm{L} 40$ & 1995-2014 & Weekly & 4 & 440 & $102(183)$ & $156(99)$ \\
\hline ECMWF & Tco639/319 L91 & 1998-2017 & 2 per week & 11 & 860 & $202(365)$ & $327(161)$ \\
\hline HMCR & $1.1^{\circ} \times 1.4^{\circ} \mathrm{L} 28$ & 1985-2010 & Weekly & 10 & 572 & $134(231)$ & $222(117)$ \\
\hline ISAC & $0.75^{\circ} \times 0.56^{\circ} \mathrm{L} 54$ & $1981-2010$ & $\begin{array}{l}\text { Every } \\
5 \text { days }\end{array}$ & 5 & 840 & $203(389)$ & 309 (158) \\
\hline JMA & $\begin{array}{l}\text { TL479/ } \\
\text { TL319 L100 }\end{array}$ & 1981-2012 & 3 per month & 5 & 480 & $121(203)$ & $188(89)$ \\
\hline KMA & N216 L85 & 1991-2010 & 4 per month & 3 & 400 & $100(169)$ & $149(81)$ \\
\hline NCEP & T126 L64 & 1999-2010 & 6 per month & 4 & 360 & $74(164)$ & $116(80)$ \\
\hline UKMO & N216 L85 & 1993-2015 & 4 per month & 7 & 460 & $119(187)$ & $183(89)$ \\
\hline
\end{tabular}

200 and $850 \mathrm{hPa}$ and OLR. The data from KMA do not include the OLR variable, which is required for the MJO index calculation, and thus are excluded in the MJO skill evaluation. However, the 200- and 850-hPa zonal wind data of the KMA reforecast are used in the diagnostic analysis. Reforecasts initialized in the extended boreal winter from November to March are analyzed. As several models produce reforecasts on the fly for certain days of the week, the dates of the reforecasts for those models correspond to the weeks in the winter of 2017/18. Therefore, the model versions used correspond to the real-time forecast during that period, which are not the most updated for several models. All available reforecasts are utilized, except for the CMA and NCEP models, which have reforecasts initialized every day. For these two models, we take the reforecasts initialized six times per month on the 1st, 6th, 11 th, 16th, 21st, and 26th of each month, so that they have a sample frequency similar to other models.

For MJO prediction skill verification we use observed data corresponding to the reforecast period of each model. In the diagnostic analysis, the ERA-Interim and NOAA satellite-derived OLR data from 1981 to 2017 are used. The number of forecasts for each model can be found in Table 1. All the data are interpolated to a $2.5^{\circ} \times 2.5^{\circ}$ grid before the analysis.

The MJO forecast skill is assessed using the real-time multivariate MJO indices (RMM1 and RMM2; Wheeler and Hendon 2004), which are defined as the principal components of the two leading modes of the empirical orthogonal function (EOF) analysis of the combined fields of $15^{\circ} \mathrm{S}-15^{\circ} \mathrm{N}$ meridionally averaged OLR and zonal winds at 850 and $200 \mathrm{hPa}$. The MJO index is calculated following the procedure described in previous studies (e.g., Gottschalck et al. 2010; Vitart 2017). In brief, the zonal wind at 200 and $850 \mathrm{hPa}$ and OLR are averaged between $15^{\circ} \mathrm{N}$ and $15^{\circ} \mathrm{S}$. Forecast anomalies are calculated by removing the climatology of reforecast ensemble mean, which is dependent on lead time. The previous 120-day average is removed from the anomaly data for each day to minimize the influence of interannual variability. To do that for the reforecast, the past 120 days of observed anomalies
(ERA-Interim and NOAA OLR) are appended before the reforecast initialization day. The resulting OLR, U850, and U200 anomaly fields are projected onto the two precomputed combined EOF structures and normalized with the precomputed coefficients from Wheeler and Hendon (2004) to obtain RMM1 and RMM2.

The NAO index used in this study is only for the initial states. It is not possible to calculate the initial NAO index for all models from the S2S database, because not all centers provide the output data for $t=0$. All the models are operational, and their initial conditions are very close to the reanalysis. Therefore, the daily NAO index (NAOi) is downloaded from the Climate Prediction Center (CPC) website (ftp://ftp.cpc.ncep.noaa.gov/cwlinks/norm.daily.nao.index. b500101.current.ascii), which is calculated as a projection of daily 500-hPa geopotential height anomalies poleward of $20^{\circ} \mathrm{N}$ onto the NAO pattern, which was identified using the rotated principal component analysis (RPCA) as described in Barnston and Livezey (1987). In the following, we use NAOi to represent the NAO. The conclusions presented in this study are not sensitive to the definition of the NAO index, as in LB2011 where similar results were obtained the NAO index was calculated differently.

MJO prediction skill is measured using the bivariate anomaly correlation coefficient (BCOR) between the forecast and observed RMM1 and RMM2 indices (e.g., Lin et al. 2008; Rashid et al. 2011; Vitart 2017; Lim et al. 2018).

To assess the impact of the NAO on the MJO prediction skill, the reforecasts are categorized according to the amplitude and phase of the NAO index in the initial condition. A strong NAO is selected when the initial NAO index amplitude is greater than 1 (i.e., $|\mathrm{NAOi}|>1$ ), while a weak NAO refers to $|\mathrm{NAOi}|<0.5$. A positive NAO is defined when the initial $\mathrm{NAOi}>0.5$, and the criterion of NAOi $<-0.5$ is used for a negative NAO. Calculations were repeated with different criteria for defining weak NAO (e.g., $|\mathrm{NAOi}|<0.65$ ), and positive and negative NAO (e.g., NAOi $>0.0$ and NAOi $<0.0$ ). The results presented below are in general insensitive to the details of the definition. The number of reforecasts for each 
category is also listed in Table 1 . As many models have a small ensemble size in the reforecast, it is difficult to assess the spread among ensemble members. For assessing the impact of NAO on the MJO prediction skill, only the ensemble mean is analyzed.

\section{NAO influence on the MJO in the S2S models}

\section{a. MJO phase}

The observational study of Lin et al. (2009) revealed that there is a significant lagged association between the NAO and MJO. A negative NAO leads MJO phases 2-3 by about three weeks, and MJO phases 6-7 tends to occur about three weeks after a positive NAO. To see if this lagged NAO-MJO connection is present in the S2S models, the probability of occurrence of each MJO phase in the forecast period at lead time 21 to 30 days is assessed when initialized with a positive and negative NAO (Fig. 1). Here we show the ratio of days for each MJO phase to the total reforecast days in that period. The top left panel is from observations using the MJO index calculated from the ERA-Interim reanalysis and the NOAA satellite-derived OLR. Consistent with Lin et al. (2009), there is more frequent occurrence of $\mathrm{MJO}$ phases 7-8 following a positive NAO than a negative NAO, and MJO phases $2-3$ is more likely to occur after a negative NAO. This frequency shift of MJO phase following positive and negative NAO is well represented in most of the S2S models, although to different degrees. This indicates that the influence of the $\mathrm{NAO}$ on the tropical MJO is a robust process that can be reasonably well predicted by most dynamical models.

\section{b. Tropical $U 200$}

To investigate how the NAO excites the MJO and whether this process is captured in the model, we begin by looking at the evolution of the zonal winds at $200 \mathrm{hPa}$ as a function of latitude (Fig. 2). Following LB2011, we present the difference between positive and negative daily NAO composites for ERA-Interim and the model forecast, averaged between $0^{\circ}$ and $90^{\circ} \mathrm{E}$. We assume the response to positive and negative $\mathrm{NAO}$ is linear. From Fig. 2a, the observed upper troposphere westerly anomaly in the high-latitude Northern Hemisphere $\left(60^{\circ}-90^{\circ} \mathrm{N}\right)$ after a positive NAO tends to persist through the whole month. Most models can capture this zonal wind persistence in the high latitudes (Figs. 2b-1), although to different degrees. The S2S models have an NAO prediction skill of 12-17 days when the correlation between the forecast and observed NAO indices drops to 0.5 (Feng et al. 2021). Associated with a positive initial NAO, the observed U200 anomaly shows easterly and westerly anomalies near $45^{\circ}$ and $30^{\circ} \mathrm{N}$, respectively, which last for about 15 days (Fig. 2a). Most models appear to be able to predict this midlatitude zonal wind persistence as well, but several models have these zonal wind anomalies too persistent. In the tropical region, the observed U200 anomaly shows little signal for the first 20 days except a weak easterly anomaly near $15^{\circ} \mathrm{N}$ at the beginning (Fig. 2a). The initial easterly anomaly near $15^{\circ} \mathrm{N}$ is seen in most models. At around day 20 , there is a dramatic increase of westerly wind anomaly near the equator and the anomalous westerly wind remains significant until the end of the month. This westerly anomaly that suddenly appears in the equatorial upper troposphere about three weeks following a positive NAO is what influences the tropical MJO. Corresponding to upper westerly wind anomaly over the tropical Indian Ocean, the convective activity in the Indian Ocean is suppressed, which leads to MJO phase 7 as is demonstrated in Fig. 1. The reverse is true for negative NAO and MJO phase 3. This strong increase of $200-\mathrm{hPa}$ westerly anomalies near the equator about three weeks following an initial positive NAO is evident in the BOM, CMA, ECCC, JMA, KMA, and UKMO models. Some indication of equatorial westerly wind increase is also seen in the CNRM, ISAC, and ECMWF models.

To further understand the influence of NAO on the tropical circulation, we look at the spatial distribution of the U200 anomaly following positive and negative NAO. Shown in Fig. 3 is the difference of composites of the U200 anomaly between positive and negative NAO cases averaged for the lead time of 21-30 days, again assuming a linear response to positive and negative NAO. In the observation (Fig. 3a), we see that following a positive NAO there is a strong westerly anomaly at $200 \mathrm{hPa}$ across the subtropical North Atlantic. To the east in the tropics from central Africa to the Maritime Continent, a significant westerly wind anomaly is observed, corresponding to what we see in Fig. 2 over the equator from days 21-30. All the S2S models can predict the enhanced westerly U200 wind across the subtropical North Atlantic 21-30 days following a positive NAO (Figs. 3b-1). Over the tropical Indian Ocean, all the models can predict positive U200 anomalies as well. The amplitude of the response, however, is model dependent. In the CNRM and NCEP models, the westerly U200 anomaly center over the Indian Ocean is shifted westward and less significant than the other models. It is possible that the performance in the tropical U200 response to NAO is related to model systematic error.

Another feature of interest in the observed tropical U200 anomaly field following a positive NAO is seen in the equatorial eastern Pacific, where strong westerly anomalies appear near the equator off the west coast of South America that extend both northwestward and northeastward (Fig. 3a). The northeastward extension appears to be connected to the westerly anomalies in the subtropical North Atlantic. To the west of the westerly anomaly center is an equatorial easterly anomaly region. This upper easterly anomaly is likely connected to the $850-\mathrm{hPa}$ westerly anomaly and enhanced convection in the equatorial western-central Pacific which forms the east convection center of MJO phase 7, as will be shown in the next subsection. A positive U200 anomaly center is seen in the subtropical Southern Hemisphere. These three U200 anomaly centers in the eastern Pacific appears to indicate an inter-hemispheric interaction in this region. In boreal winter, the seasonal mean zonal wind in the equatorial central Pacific is westerly, which provides a favorite condition for Rossby waves to propagate cross the equator into the other hemisphere (e.g., Webster and Holton 1982). Most of the S2S 


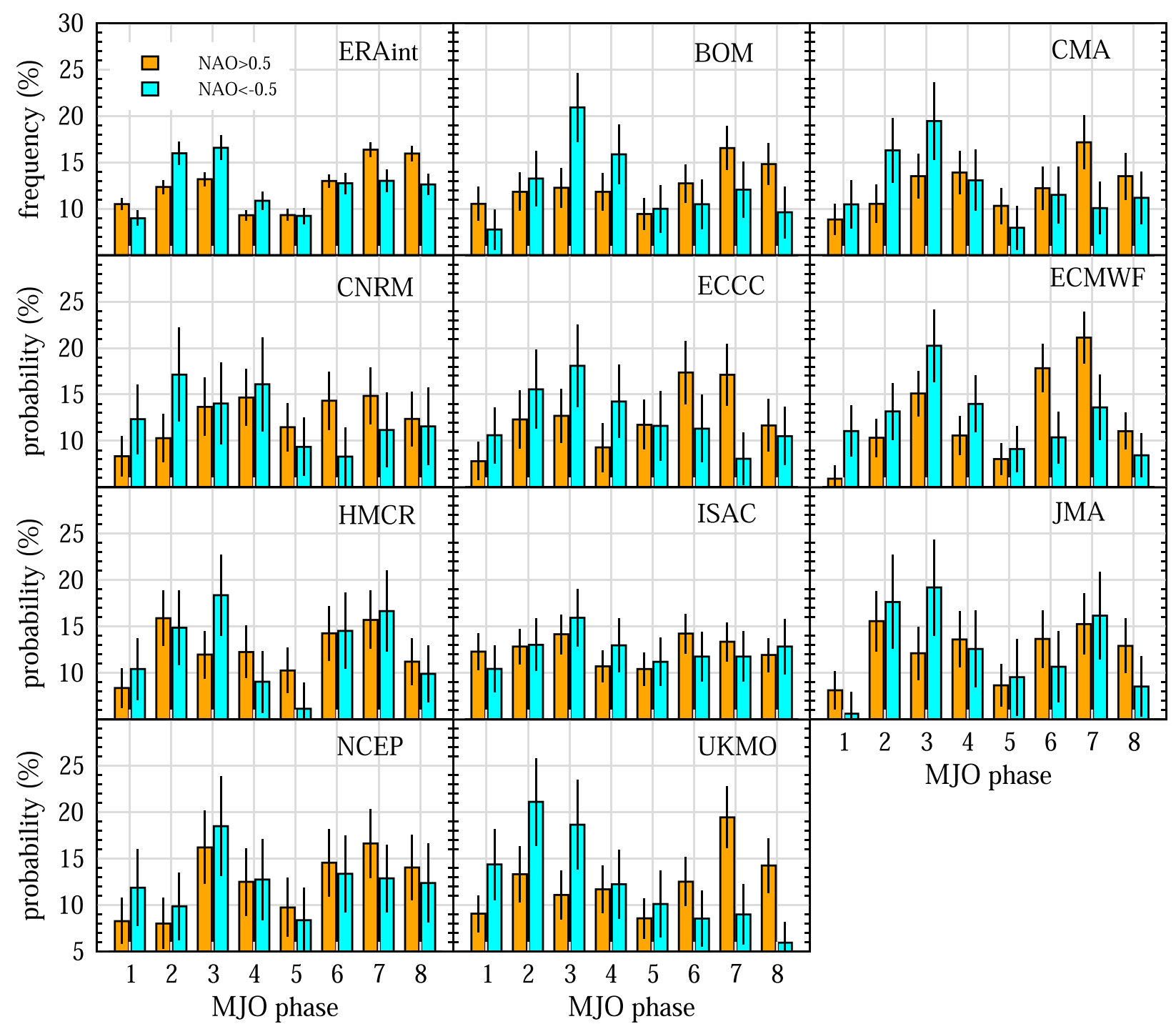

FIG. 1. (top left) Observed 21-30-day lagged occurrence frequency of MJO phases following positive and negative NAO in extended winters of 1981-2017. The remaining panels show the probability of occurrence of MJO phases in the forecast period of 21-30 days initialized with positive and negative NAO for individual S2S models. The vertical bars represent the $95 \%$ level of confidence from a 10000 bootstrap resampling calculation.

models are also able to predict this equatorial eastern Pacific feature of the U200 anomaly.

\section{c. Tropical U850 and OLR}

Not only does the tropical upper troposphere zonal wind respond to the NAO variability, but the low-level zonal wind and convective activity are also affected. Figure 4 shows the counterparts of Fig. 3 for U850 (in contour) and OLR (in color) - that is, the difference of composites between positive and negative NAO cases averaged for the lead time of 2130 days. In the equatorial Indian Ocean where a strong 200-hPa westerly wind anomaly is located (Fig. 3a), an easterly wind anomaly at $850 \mathrm{hPa}$ and suppressed convection are observed, whereas in the western-central Pacific an $850-\mathrm{hPa}$ westerly anomaly and enhanced convection are found, with a structure like $\mathrm{MJO}$ phase 7. A majority of the $\mathrm{S} 2 \mathrm{~S}$ models can predict the 850-hPa westerly wind anomaly and suppressed convective activity three weeks after being initialized with a positive NAO (Figs. 4b-1), although the amplitude and exact location are model dependent.

\section{MJO forecast skill dependence on NAO amplitude}

Given the models' ability of capturing the lagged NAO$\mathrm{MJO}$ connection as discussed above, it is of interest to explore whether and how the NAO influences the MJO prediction skill. In this section we look at the dependence of MJO prediction skill on the NAO amplitude in the initial condition.

Figure 5 compares the MJO BCOR prediction skill as a function of lead time for all reforecasts, and for those 
a) ERA-interim

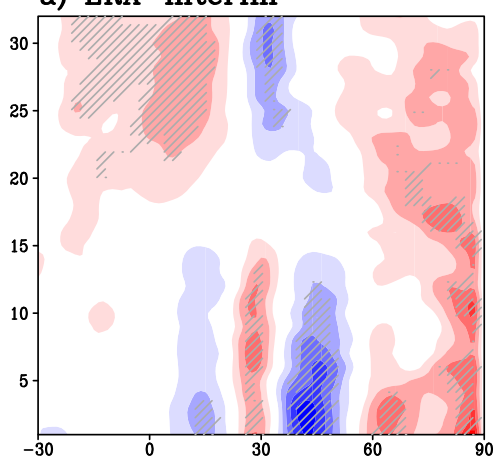

d) CNRM

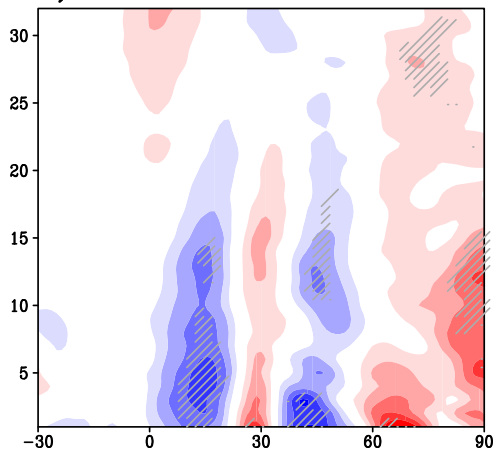

g) HMCR

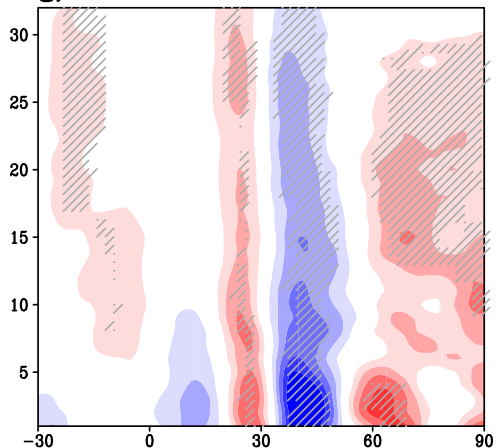

j) KMA

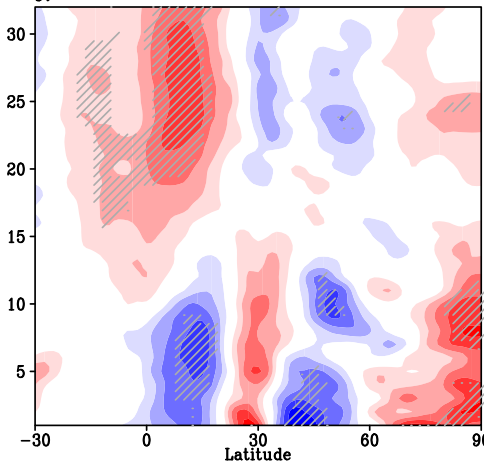

b) $\mathrm{BOM}$

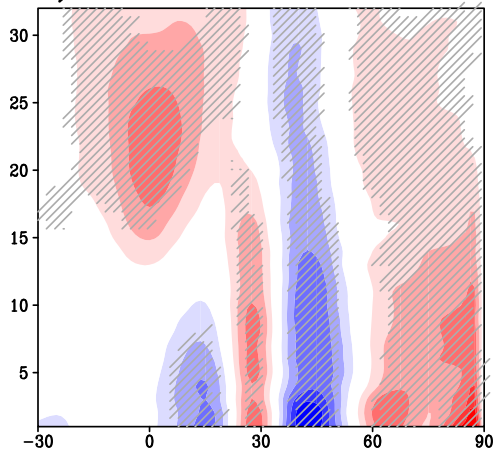

e) $\mathrm{ECCC}$

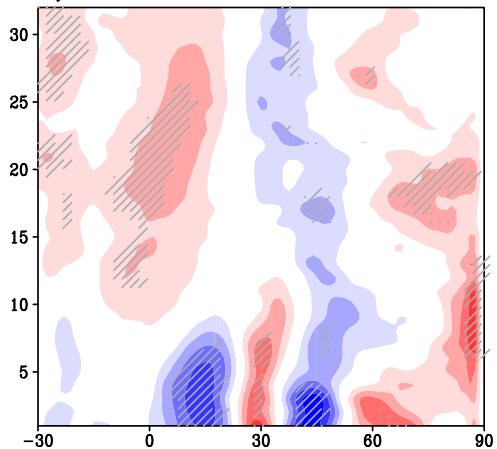

h) ISAC

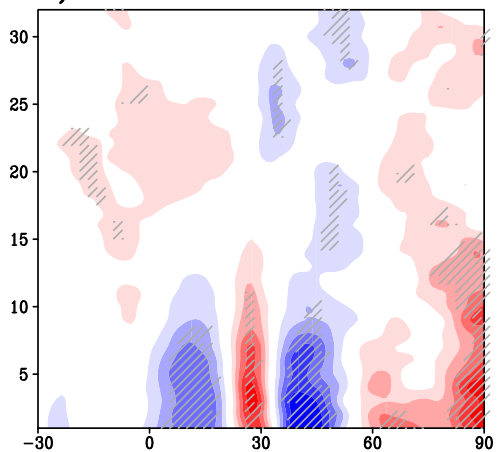

k) NCEP

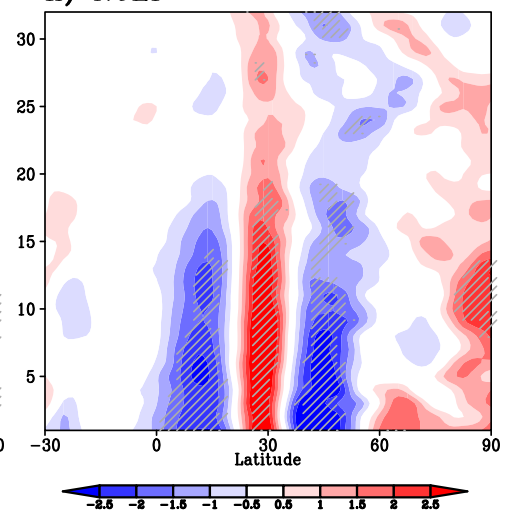

c) CMA

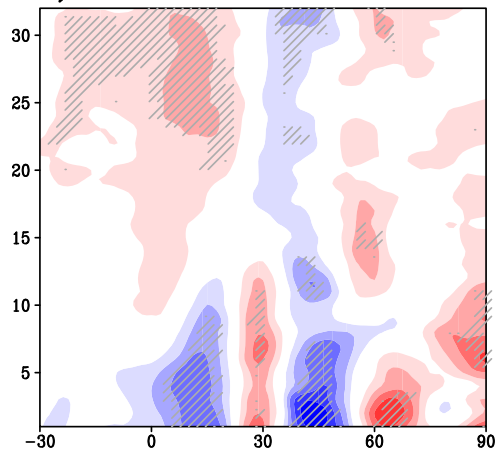

f) ECMWF

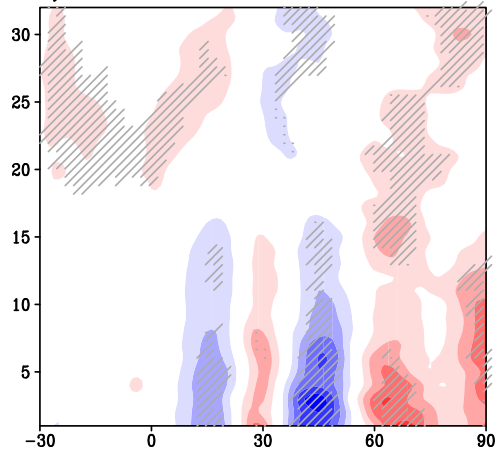

i) JMA

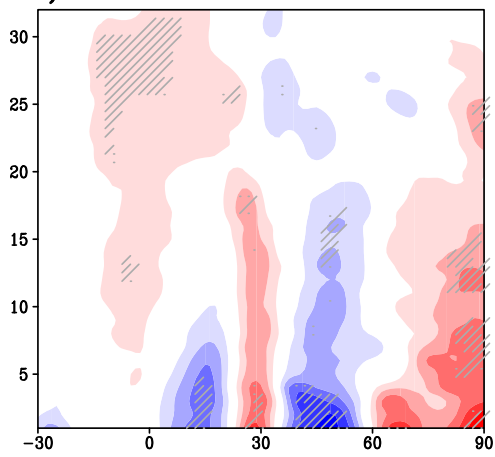

1) UKMO

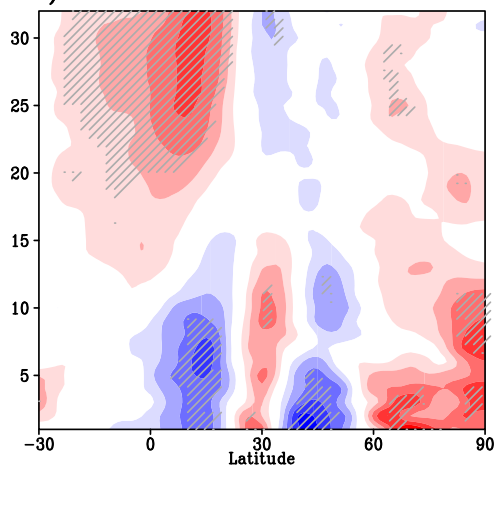

FIG. 2. Difference of U200 anomaly $\left(\mathrm{m} \mathrm{s}^{-1}\right)$ between positive and negative NAO composites averaged from $0^{\circ}$ to $90^{\circ} \mathrm{E}$, as a function of latitude (horizontal axis) and lead time (vertical axis) in days. The hatched areas indicate that the difference is statistically significant at the 0.05 level according to a Student's $t$ test. 

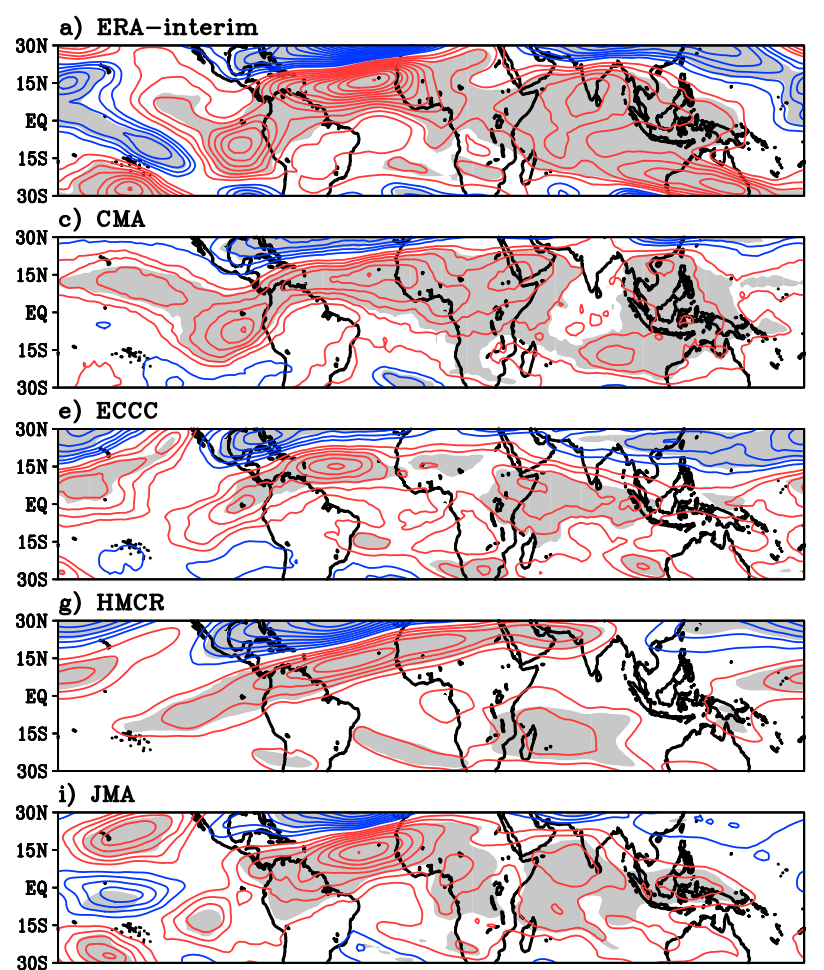

30N k) NCEP

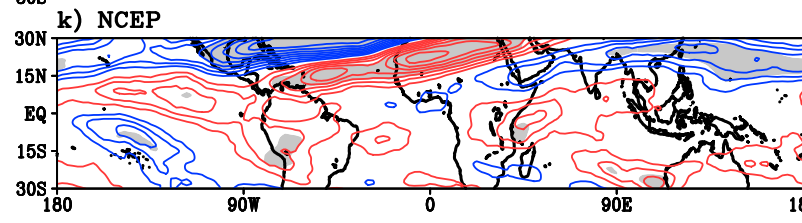

b) $\mathrm{BOM}$

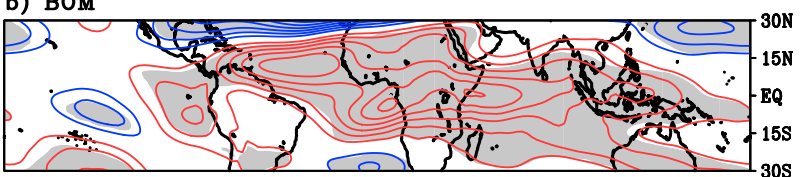

d) CNRM

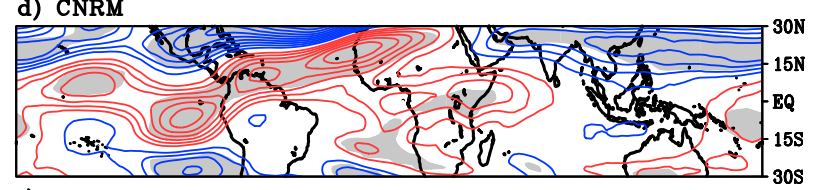

f) ECMWF

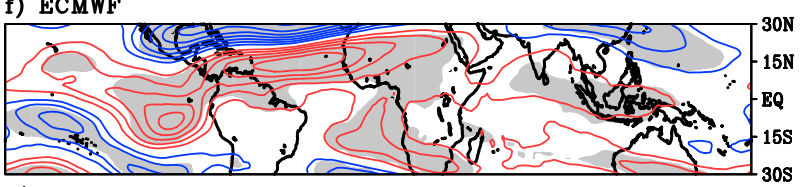

h) ISAC

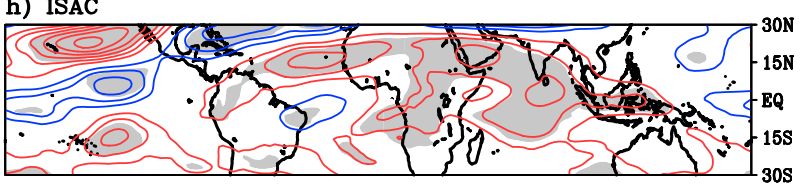

j) KMA

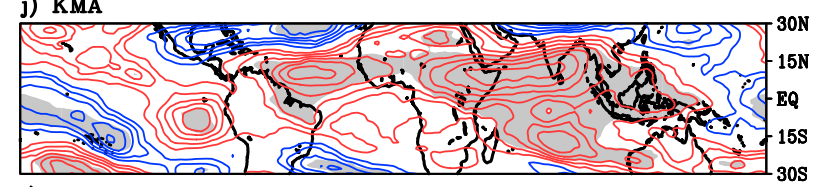

1) UKMO

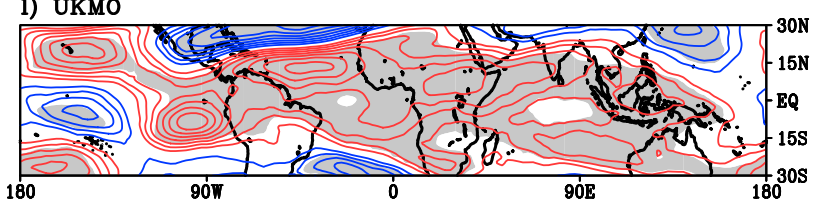

FIG. 3. Spatial distribution in the tropical region for the difference between positive and negative NAO composites of U200 anomaly in the forecast period of 21-30 days. Positive and negative values are plotted in red and blue contours, respectively. The contour interval is $0.5 \mathrm{~m} \mathrm{~s}^{-1}$. The contour for the value of zero is omitted. The shaded area indicates that the difference is statistically significant at the 0.05 level.

initialized with strong and weak NAO. The general skill when all reforecasts are considered (black curve) is consistent with previous studies using the same S2S models (e.g., Vitart 2017; Lim et al. 2018), which shows significant model-to-model variation in $\mathrm{MJO}$ prediction skill. For most models little difference in MJO skill between strong and weak NAO can be seen for lead time shorter than 15 days. However, notable difference of skill emerges for a lead time longer than 20 days. Forecasts initialized with a strong NAO have better MJO prediction skill than those starting from a weak NAO. This result is consistent with LB2011, who compared the MJO skill between strong and weak NAO in the reforecast using an early version of the ECCC atmospheric model. The $\sim 3$-week delayed difference of MJO prediction skill between weak and strong NAO initialized reforecasts reflects the observed lagged NAO-MJO connection as reported in Lin et al. (2009), and is also consistent with the MJO response in these S2S models as discussed in section 3 .

Another measure of MJO prediction skill is the lead time in days when the correlation skill drops to 0.5 , which has been used in many previous studies to be indicative of the limit of a skillful forecast (e.g., Murphy and Epstein 1989). Summarized in Fig. 6 is the number of days for which the RMM BCOR drops to 0.5 for all the S2S models. For almost all the models the MJO skill is higher when the reforecast is initialized with strong NAO than weak NAO. The difference for half of the models is statistically significant. When all reforecast cases are included, only one model (ECMWF) has an MJO prediction skill longer than 30 days (32.1 days). However, when the reforecasts initialized with strong NAO are considered, three models (BOM, ECMWF, and NCEP) produce an MJO skill over 30 days (32.2, 35.2, and 32.1 days, respectively). The increase of skill from weak NAO to strong NAO initialized reforecasts is 7.7, 5.8 , and 10.3 days, respectively, for these three models.

The RMM index consists of three components, U200 and U850 for circulation and OLR for convection. Several previous studies have pointed out that the RMM index may be dominated by the circulation and perhaps does not represent as well the convection of the MJO (e.g., Straub 2013; Ventrice et al. 2013). It would be interesting to see how these three individual MJO components are influenced by the NAO. Here each component of the RMM index is computed by projection of 

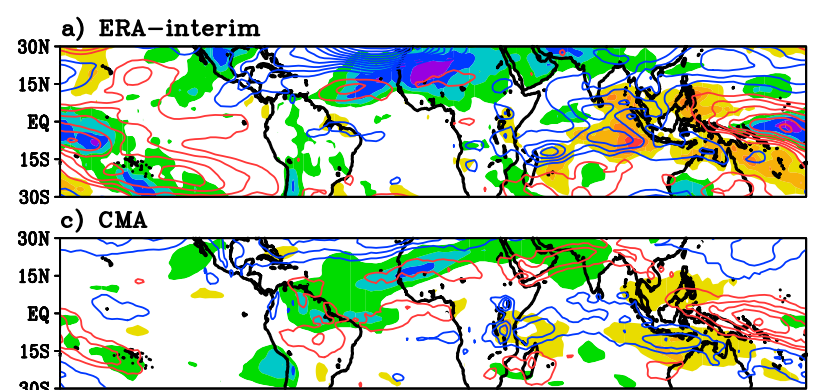

e) ECCC

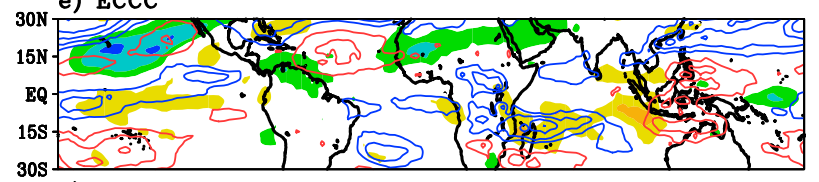

gos HMCR
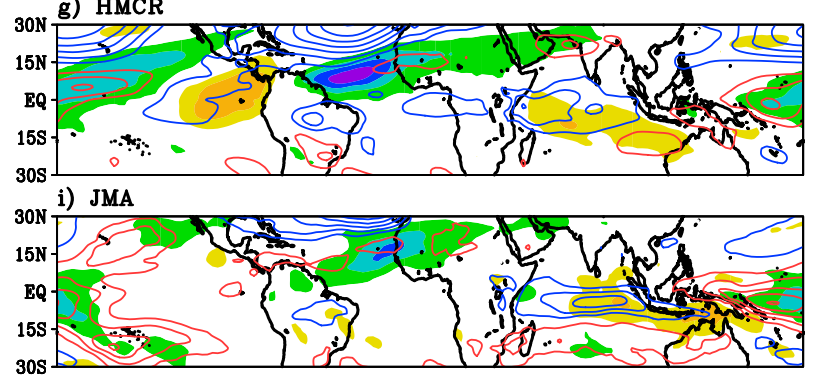

30N $\frac{\text { k) NCEP }}{2}$

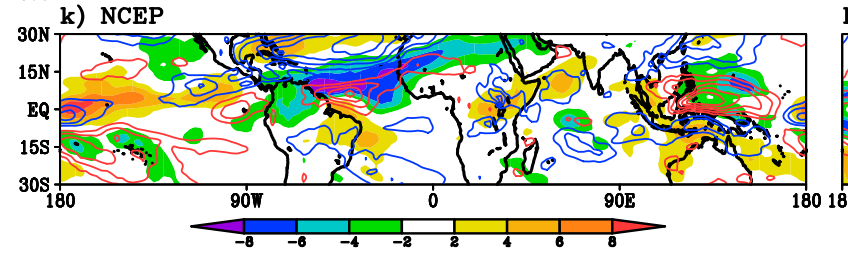

FIG. 4. Difference between positive and negative NAO composites of U850 anomaly (contours) and OLR anomaly (color; W m ${ }^{-2}$ ) in the forecast period of 21-30 days. Positive and negative values of U850 anomaly are plotted in red and blue contours, respectively. The contour interval is $0.25 \mathrm{~m} \mathrm{~s}^{-1}$. The contour for the value of zero is omitted. Note that KMA does not have OLR data.

\section{b) BOM}

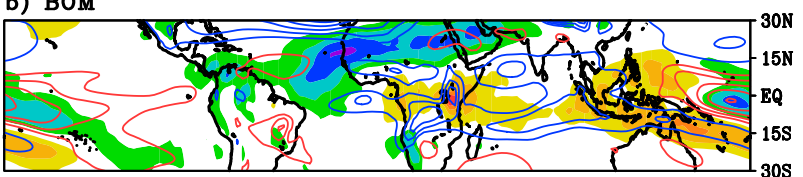

\section{d) CNRM}

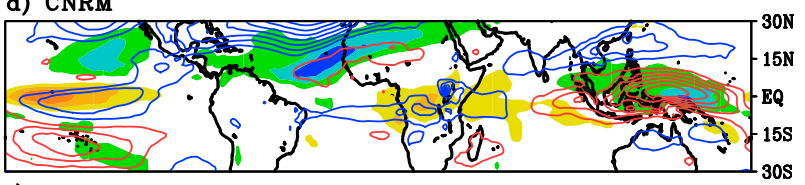

\section{f) ECMWF}

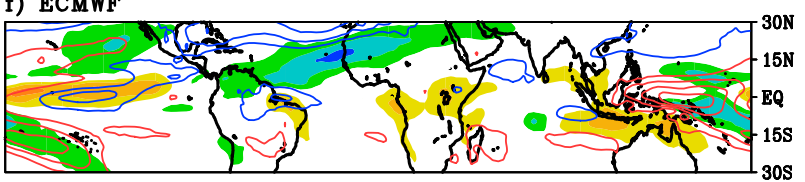

h) ISAC
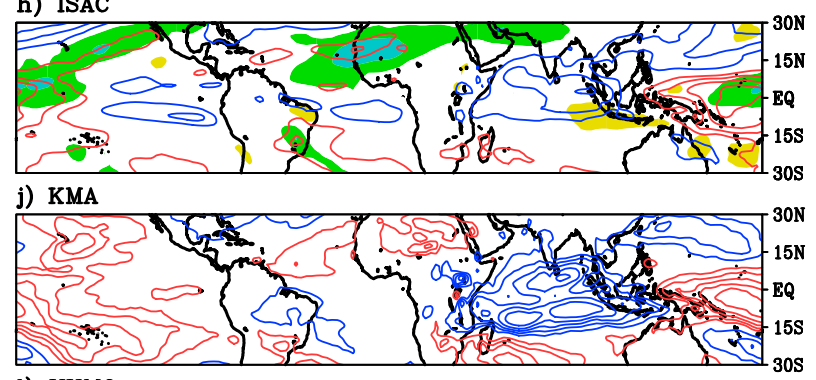

1) UKMO

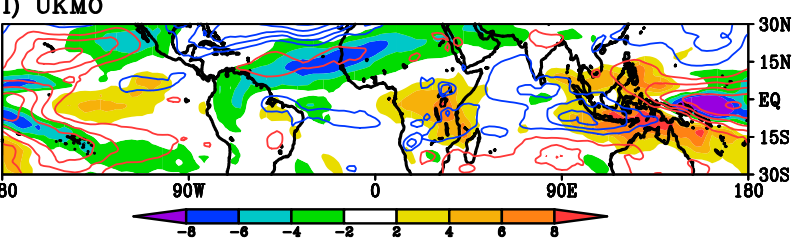

only that one variable onto the EOF structures of that variable. Considering that it takes about three weeks for the NAO to influence the MJO (Lin et al. 2009) and that the difference in MJO prediction skill between strong and weak NAO reforecasts becomes clear after 20 days for most models (Fig. 5), we calculate the BCOR skill averaged between the lead time of 21 and 30 days. Shown in Fig. 7 is the 21-30-day averaged BCOR skill for RMM and each individual component for $10 \mathrm{~S} 2 \mathrm{~S}$ models. In general, for most models the skill of the circulation components (U200 and U850) is slightly higher than the convection component (OLR), consistent with previous studies (e.g., Lin et al. 2008; Kim et al. 2014). The difference between strong and weak NAO initialized reforecasts agrees with Figs. 5 and 6: almost all S2S models have higher MJO skill when initialized with strong NAO than with weak NAO. This same conclusion can be drawn for all the three components of the MJO (i.e., U200, U850, and OLR). This indicates that the NAO influences not only the MJO-related U200 skill, but also the U850 and convection components.

The above results are for the variables projected onto the MJO structure as depicted by the RMM, which has a large-scale structure. Whether or not the NAO can influence the general forecast skill of these variables in the tropical Indian Ocean and western Pacific region is also of interest. To assess this, the anomaly correlation of each variable is calculated between the forecast and observation at each grid point and then averaged over the region of $60^{\circ}-150^{\circ} \mathrm{E}, 15^{\circ} \mathrm{S}-15^{\circ} \mathrm{N}$, which is the domain where most of the MJO activity is located. As no projection to the MJO is made, the skill reflects model performance in predicting variabilities of all spatial and temporal scales. The result is presented in Fig. 8 for the 11 S2S models. As the KMA model does not have the OLR data, only U200 and U850 skills are shown for this model. Neglecting for now the impact of the NAO, the forecast skill of U200 is seen to be the best. Next best is U850 followed by OLR. This indicates that the upper tropospheric circulation in the tropical Indian Ocean and western Pacific is more predictable than that in the lower troposphere. A large part of the tropical convection as represented by OLR is likely associated with small-scale features and is not well represented and predicted by the models. Comparing the regional average skill with that of the MJO, even the U200 skill is much lower than that of the MJO, 


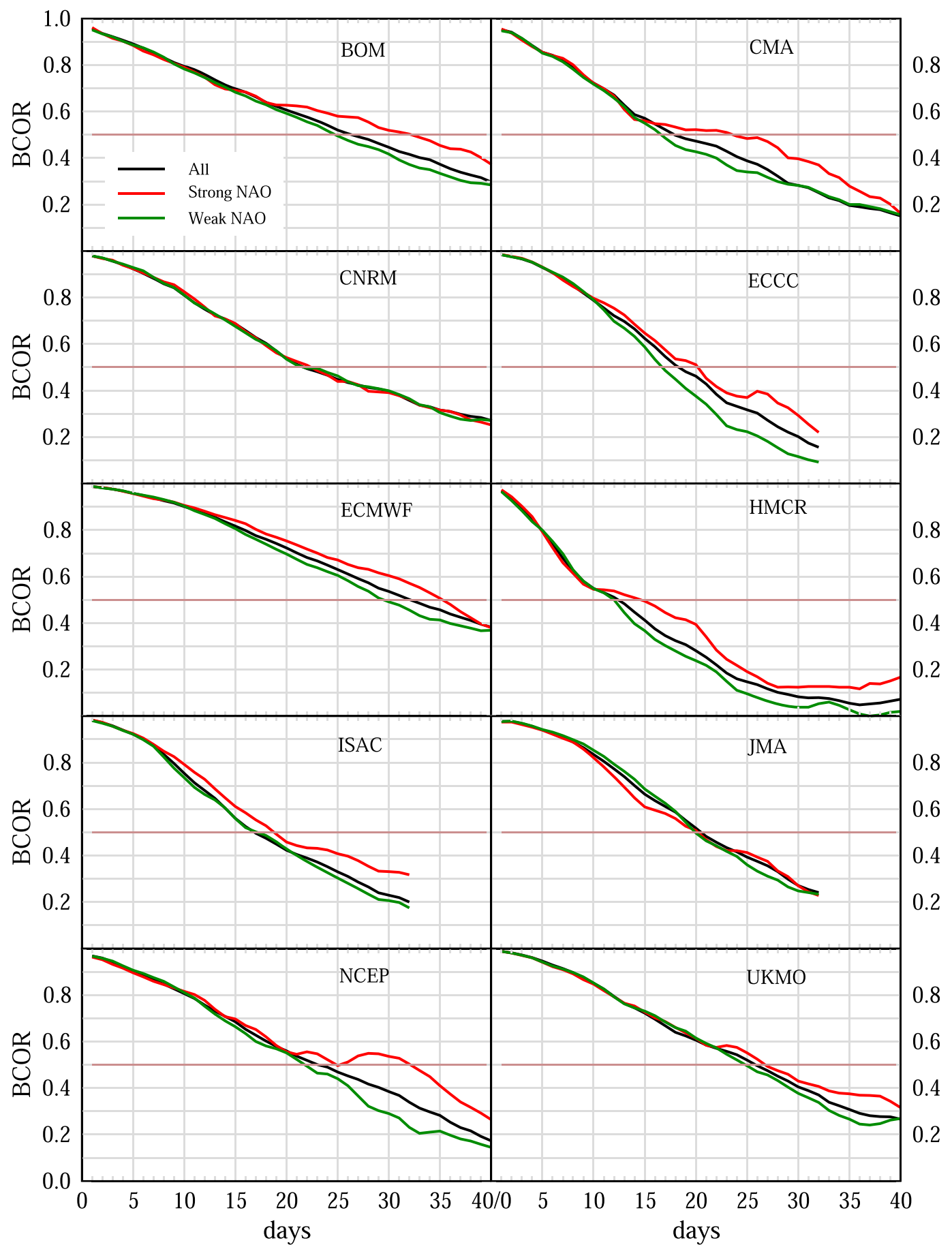

FIG. 5. MJO BCOR skill as a function of lead time for individual S2S models. The MJO prediction skill with all reforecast cases is shown in black. The MJO prediction skills for the strong and weak NAO initialized reforecasts are shown in red and green, respectively.

indicating that the MJO is more predictable than other tropical variabilities, presumably because the MJO discriminates to lower frequency and large space scales.

Comparing the skill between reforecasts initialized with strong and weak NAO (solid and dashed lines in Fig. 8), there are indications that all three variables have better skill when initialized with a strong NAO. U200 is the variable standing out with clearly higher prediction skill when initialized with a strong NAO than with a weak NAO. This is true for all the 11 models, even for the two models (CNRM and JMA) that 


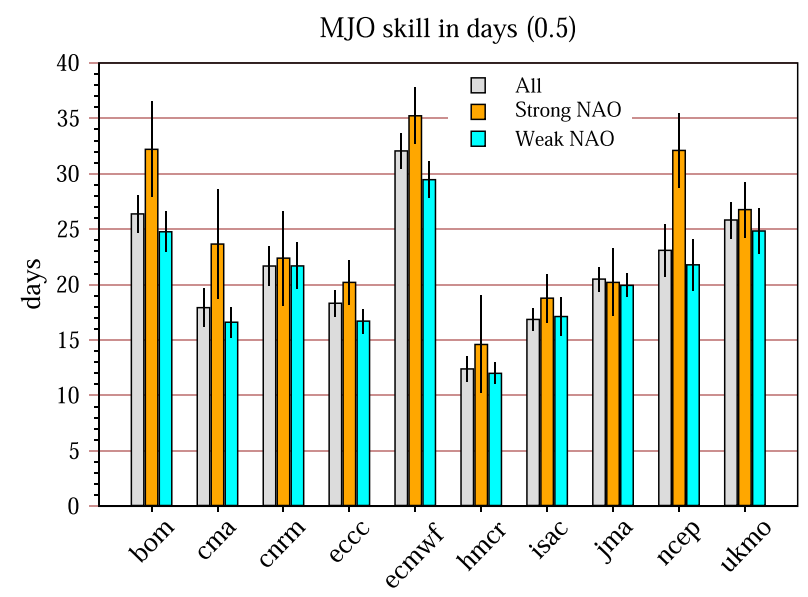

FIG. 6. Lead time in days when the correlation skill drops to 0.5 . The vertical bars represent the $95 \%$ level of confidence from a 10000 bootstrap resampling calculation.

show little difference in the MJO skill between strong and weak NAO. It is thus possible that the skill difference between strong and weak NAO initialized forecasts in this region originates in the upper troposphere. The fact that this difference extends to all the RMM components for most models as shown in Fig. 7 indicates that this upper tropospheric influence leads to tropical circulation and convection changes of the MJO.

(a) RMM average BCOR days 21-30

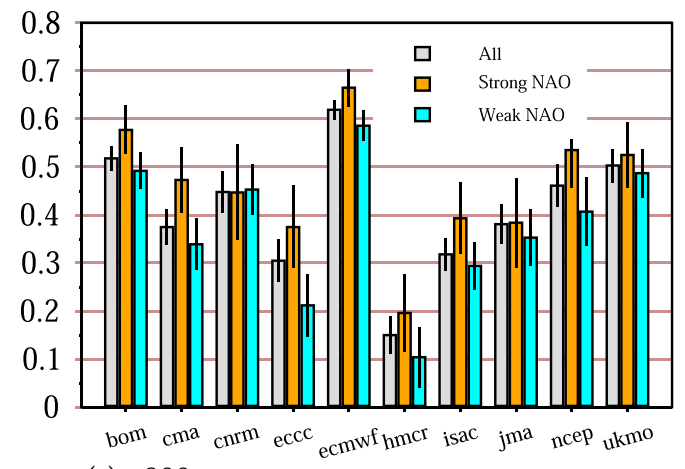

(c) u200 component

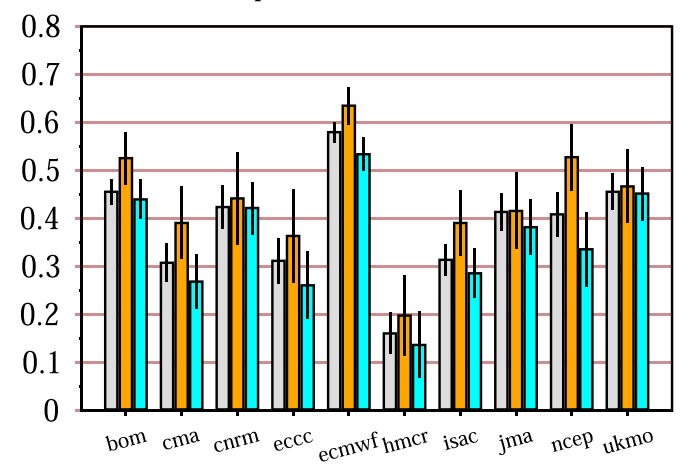

To help understand the dependence of MJO forecast skill on the amplitude of the NAO, shown in Fig. 9 is the evolution of the observed and forecast MJO amplitude following strong and weak NAO. As can be seen, in the observations (top-left panel), the MJO amplitude 15-30 days after strong NAO is stronger than after weak NAO. In most S2S models (except for the CNRM, BOM, and NCEP models), the forecast MJO amplitude is weaker than the observations, which is consistent with previous studies (e.g., Vitart 2017). It can be seen that the forecast MJO amplitude in days 15-30 for almost all S2S models is larger when initialized with strong NAO than weak NAO, similar to the observations. This indicates that the S2S models are able to capture the NAO influence on the MJO, which likely contributes to the MJO prediction skill difference as seen in Fig. 5.

\section{MJO forecast skill dependence on NAO phase}

It has been observed in previous studies that the probability density function of the NAO index is negatively skewed and extreme negative NAO events have a larger magnitude than positive extremes (e.g., Johansson 2007). Negative NAO events and related weather are found to be more persistent and more predictable (e.g., Ferranti et al. 2015; Lin 2020). Here we explore whether or not the influence of a negative NAO on the MJO prediction skill differs from that of a positive NAO.

\section{(b) OLR component}

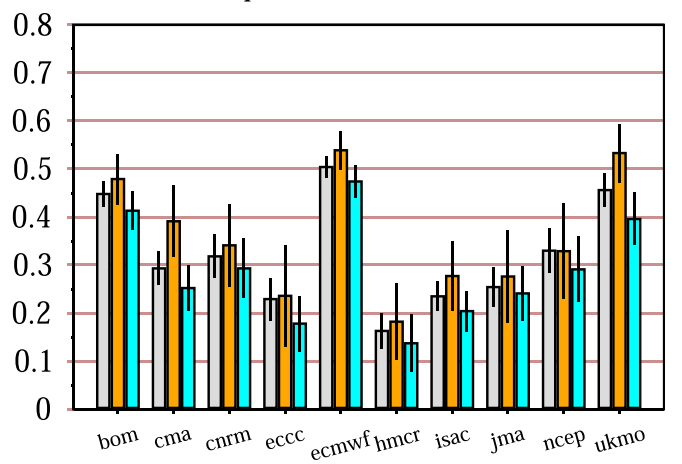

(d) u850 component

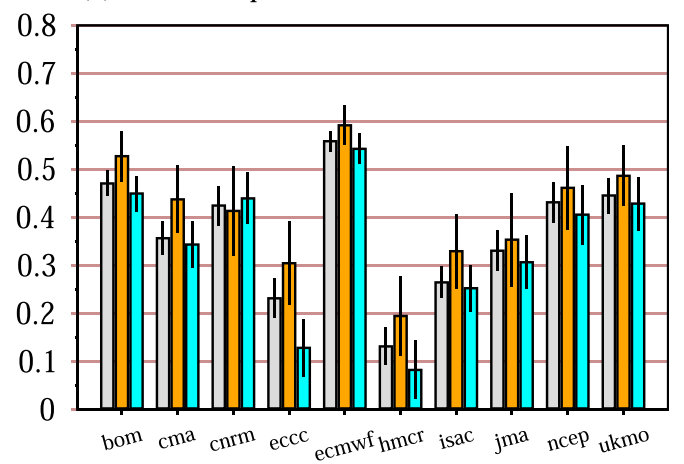

FIG. 7. The 21-30-day averaged BCOR skill for RMM and the OLR, U200, and U850 components. The vertical bars represent the $95 \%$ level of confidence from a 10000 bootstrap resampling calculation. 


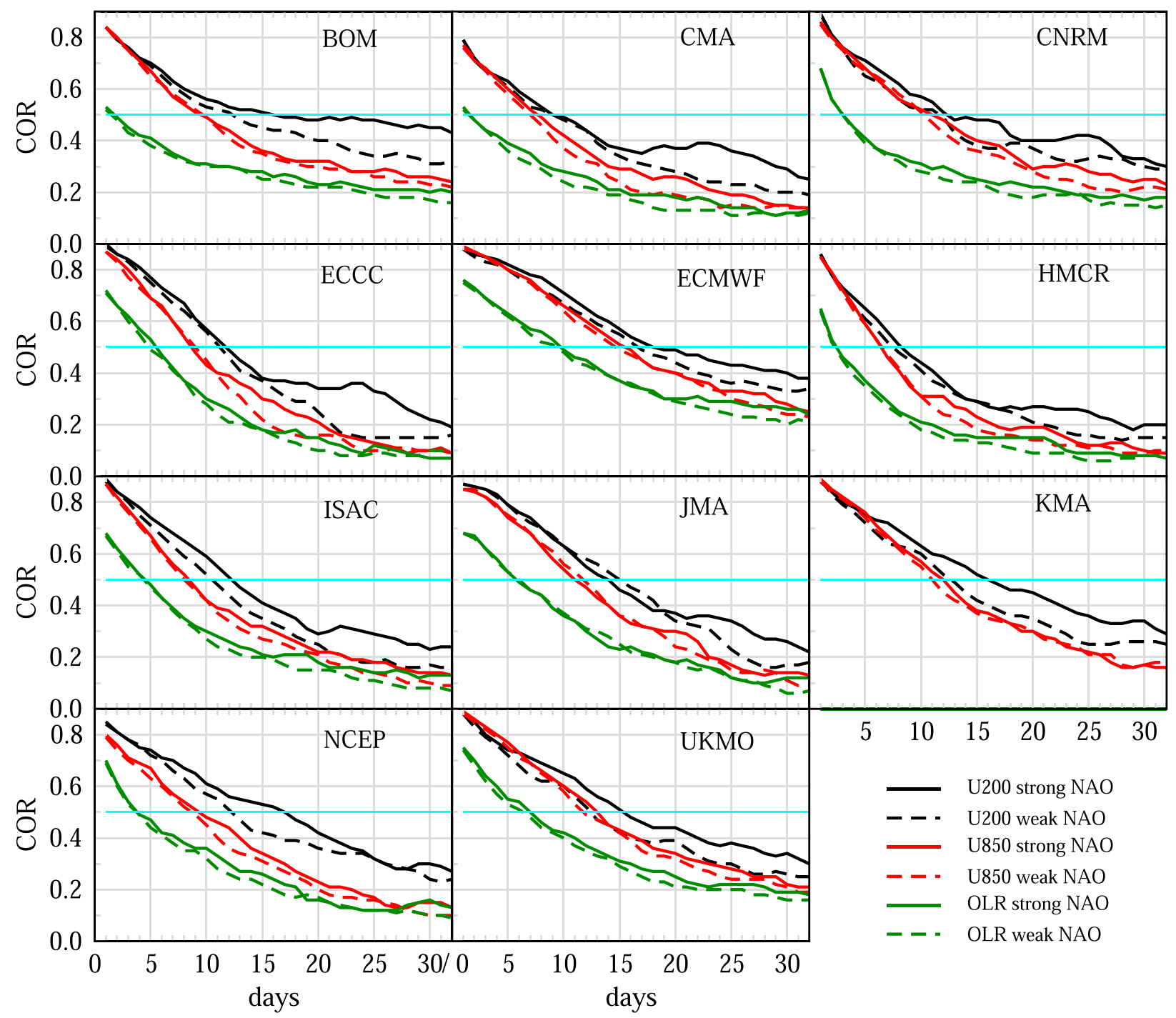

FIG. 8. Correlation skill of U200 (black), U850 (red), and OLR (green) averaged in the region of $60^{\circ}-150^{\circ} \mathrm{E}, 15^{\circ} \mathrm{S}-15^{\circ} \mathrm{N}$ as a function of lead time. The solid and dashed lines are for reforecasts initialized with strong and weak NAO, respectively. Note that KMA does not have OLR data.

We define positive and negative NAO as NAOi $>0.5$ and $\mathrm{NAOi}<-0.5$, respectively. The MJO prediction BCOR skill is compared between reforecasts initialized with positive and negative NAO in Fig. 10. Also compared (plotted in black) is the MJO skill for reforecasts initialized with weak NAO $(-0.5<\mathrm{NAOi}<0.5)$, which is the same as the green curve in Fig. 5. If we compare the BCOR skill after day 15, there are about half of the models showing that the positive NAO initialized reforecasts (red line) have better MJO forecast skill than the weak NAO forecasts (black line). However, for the negative NAO initialized reforecasts (green line), 9 out of 10 models show that the MJO prediction skill is better than weak NAO. For 6 out of 10 models (BOM, ECMWF, HMCR, JMA, NCEP, and UKMO), the forecasts starting from a negative NAO produce a more skillful MJO prediction than those from positive NAO. There is considerable difference among models in the influence of positive and negative NAO. For example, the ECMWF forecasts show a steady increase of skill for both positive and negative NAO relative to weak NAO from about day 15, whereas the UKMO forecasts show a sharp increase in skill for the negative NAO at about day 20. Sampling errors may be partially responsible for such difference. It is also possible that the NAO influence reaches the tropical MJO more easily for some models than for the others.

Figure 11 summarizes the MJO prediction skill in days for reforecasts initialized with positive and negative NAO. The negative NAO initialized forecasts produce better MJO predictions than positive NAO in six models. In general, the MJO prediction skill is high in the models when the MJO skill is sensitive to the NAO phase. The three models (BOM, ECMWF, and NCEP) that have high sensitivity to the NAO amplitude (Fig. 6) also have high sensitivity to the NAO phase. When the reforecast is initialized with negative NAO, these three models generate an MJO skill of 34.1, 39.3, and 32.3 days, respectively, 


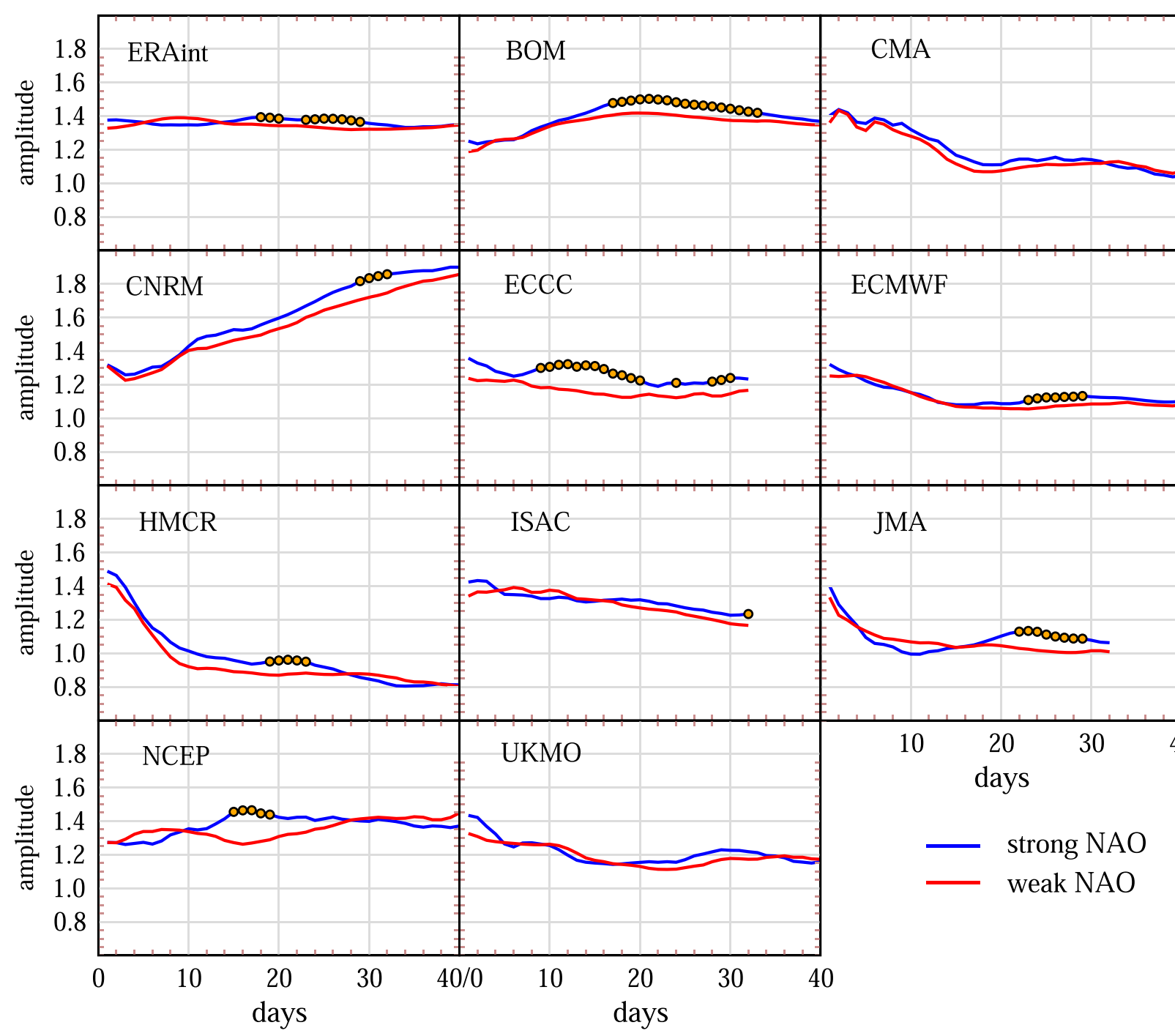

FIG. 9. (top left) evolution of composited observed MJO amplitude following strong (in blue) and weak (in red) NAO in extended winters of 1981-2017. The remaining panels show the evolution of composited forecast MJO amplitude of reforecasts initialized with strong and weak NAO for individual S2S models. Note that the composite is done using the MJO amplitude of individual ensemble members. The circles on the blue curve indicate that the difference between strong and weak NAO is statistically significant at the 0.05 level.

compared to $27.9,32.5$, and 21.5 days when the forecast starts from positive NAO.

Shown in Fig. 12 are the composites of observed initial condition for the anomaly fields of $200-\mathrm{hPa}$ geopotential height (Z200), U200, and OLR corresponding to positive and negative NAO. It should be noted that the selection of NAO cases is based on the NAO index. The average NAO index value for the positive NAO cases is 1.02 , which has almost the same strength as that for the negative NAO (-1.01). However, the negative NAO shows stronger Greenland positive and midlatitude North Atlantic negative Z200 anomalies (Fig. 12b) than their counterparts of the positive NAO (Fig. 12a). The associated easterly U200 anomaly of the negative NAO along $60^{\circ} \mathrm{N}$ North Atlantic (Fig. 12d) is also stronger than the westerly U200 anomaly of the positive NAO (Fig. 12c). In the Z200 anomaly field, over the Arabian Sea to the west of India there exists an anomalous Z200 center that appears to be part of a wave train originating from the southeast of the NAO. The negative anomaly center there of the negative NAO is stronger than the positive Z200 anomaly of the positive NAO. South of this Z200 anomaly center over the tropical Indian Ocean are westerly (easterly) U200 anomalies and suppressed (enhanced) convection near the Maritime Continent associated with negative (positive) NAO as seen in Fig. 12d (Fig. 12c). It is likely that the stronger influence of a negative NAO on the MJO is because of a stronger initial NAO circulation amplitude than a positive NAO. 


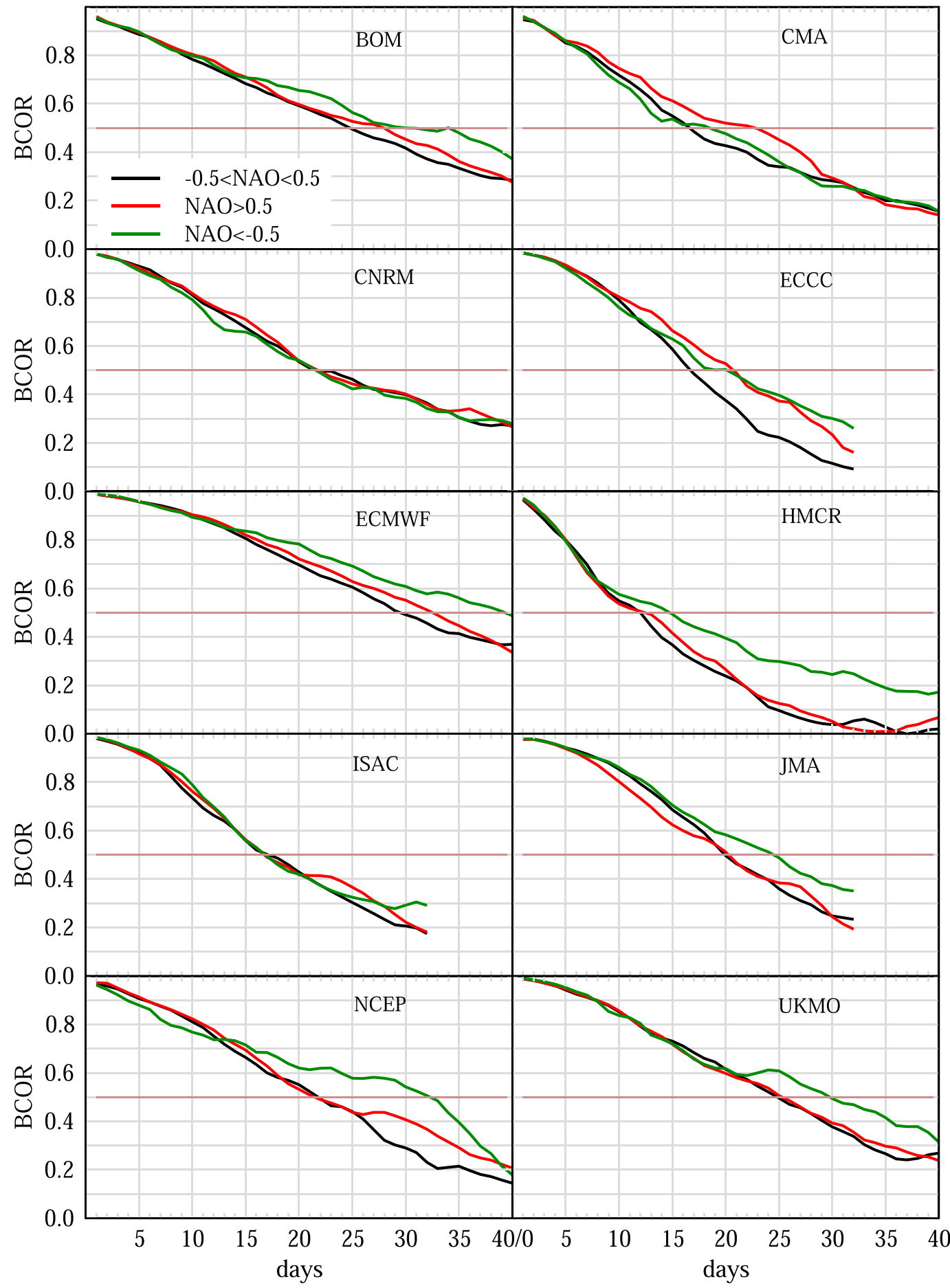

FIG. 10. MJO BCOR skill as a function of lead time. The MJO prediction skills for weak, positive, and negative NAO initialized reforecasts are shown in black, red, and green, respectively.

To verify if the MJO prediction skill difference between strong and weak (and between positive and negative) $\mathrm{NAO}$ initialized forecasts reported above is due to the influence of the MJO initial states independent of NAO, we repeated calculations of Figs. 2, 5, and 10 by excluding forecast cases with strong initial MJO (amplitude $>1$ ). The results (not shown) are very similar, indicating that the initial MJO states plays a minor role, and that the MJO prediction skill difference discussed above is caused by the NAO influence. 


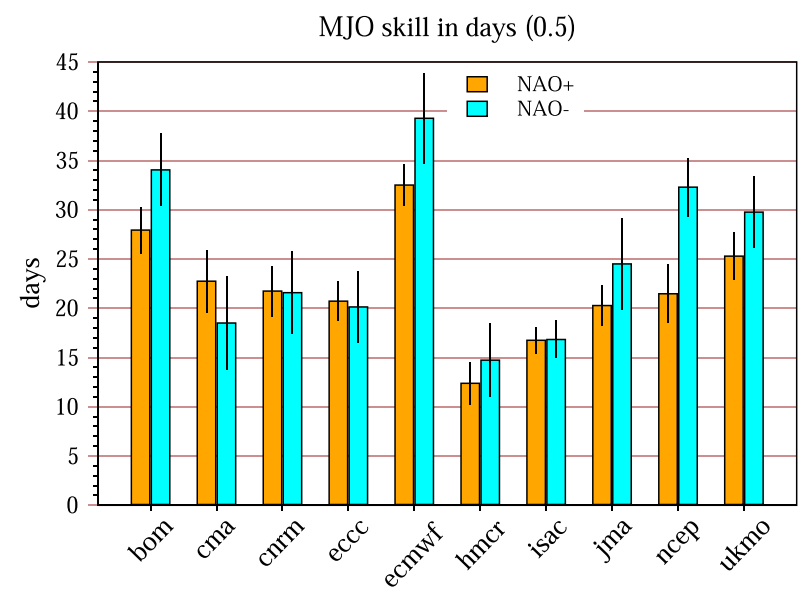

FIG. 11. Lead time in days when the correlation skill drops to 0.5 for reforecasts initialized with positive (in orange) and negative NAO (in cyan). The vertical bars represent the $95 \%$ level of confidence from a 10000 bootstrap resampling calculation.

\section{Possible mechanism}

The NAO is a large-scale extratropical mode of variability, which has an equivalent barotropic vertical structure (e.g., Wallace and Gutzler 1981; Barnston and Livezey 1987), whereas the MJO is a planetary-scale tropical disturbance coupled with convection, which has a baroclinic vertical structure in the tropics (e.g., Hendon and Salby 1994; Sperber 2003). How the signal of extratropical NAO propagates into the tropics to influence the MJO is unclear. Up to now, there has not yet been an accepted explanation for this process.

Although it is not the purpose for this study to provide a dynamical explanation for the NAO influence on the MJO, a discussion on possible mechanisms is useful. As shown in Figs. 2 and 3, significant 200-hPa westerly (easterly) wind anomalies develop over the equatorial Indian Ocean three weeks after a positive (negative) NAO. How these tropical upper tropospheric zonal wind anomalies are generated is fundamental to understand the NAO impact on the MJO.

Here we look at the lagged composites of $200-\mathrm{hPa}$ streamfunction anomaly following NAO events as well as the associated wave activity flux. Shown in Figs. 13a and $13 \mathrm{~b}$ in contour is the 21-30-day lagged $200-\mathrm{hPa}$ streamfunction anomaly composite after positive and negative NAO, respectively, calculated with the ERA-Interim data. The 200-hPa streamfunction anomaly field at the same time of a positive NAO has the same distribution as Z200 as shown in Fig. 12a, with strong negative anomalies near Greenland and positive anomalies in the midlatitude North Atlantic. At 21-30 days later, as seen in Fig. 13a, the Greenland negative center is much reduced, while the midlatitude positive center in the North Atlantic remains. In the subtropical North Atlantic, a center of strong negative 200-hPa streamfunction anomaly develops and extends all the way to South Asia. South of this negative 200-hPa streamfunction anomaly are westerly wind anomalies over the equator, consistent with Fig. 3a. Following the negative NAO (Fig. 13b), the 200-hPa streamfunction anomaly has almost the same pattern as Fig. 13a but with an opposite sign, and the amplitude is stronger. a) Z200 NAO+

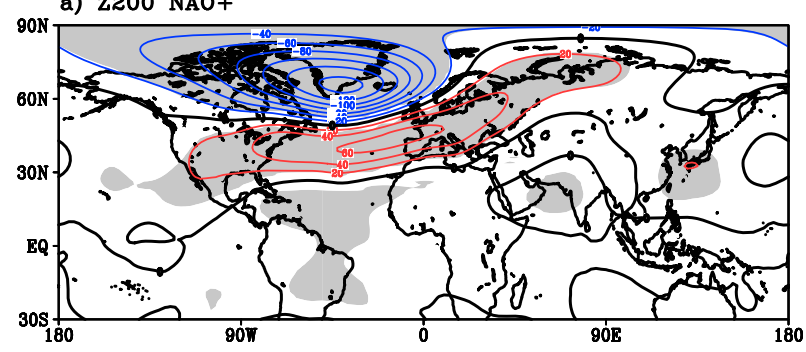

c) U200/OLR NAO+

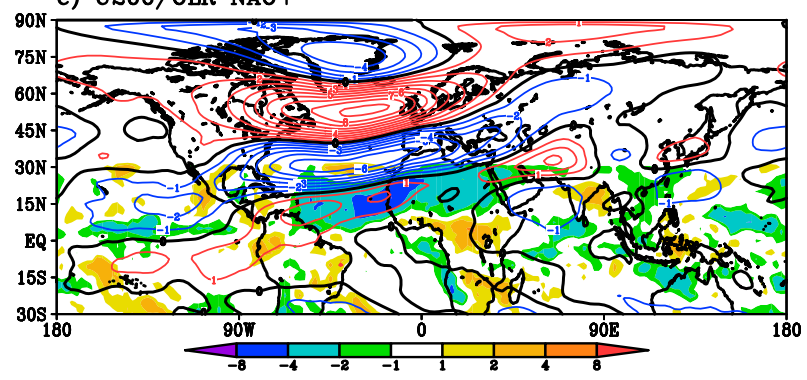

b) Z200 NAO-

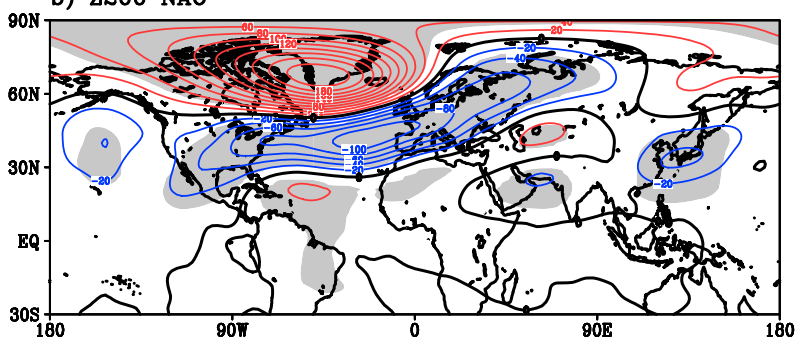

d) U200/OLR NAO-

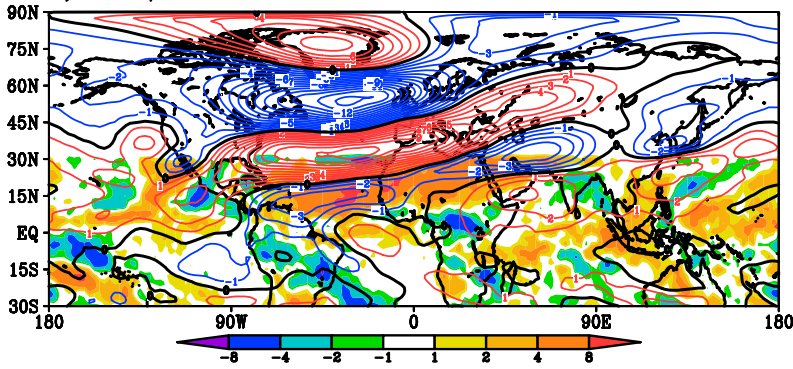

FIG. 12. Composites of observed initial condition for the anomaly fields of (a) 200-hPa geopotential height (Z200) for positive NAO, (b) Z200 for negative NAO, (c) U200 (contours) and OLR (in color) for positive NAO, and (d) U200 (in contour) and OLR (in color) for negative NAO. Contours for positive and negative values are in red and blue, respectively. The contour for zero is in black. The contour interval is $20 \mathrm{~m}$ in (a) and (b) and $1 \mathrm{~m} \mathrm{~s}^{-1}$ in (c) and (d). The shaded areas in (a) and (b) indicate that the composite anomaly is different from zero at the 0.01 significance level. 

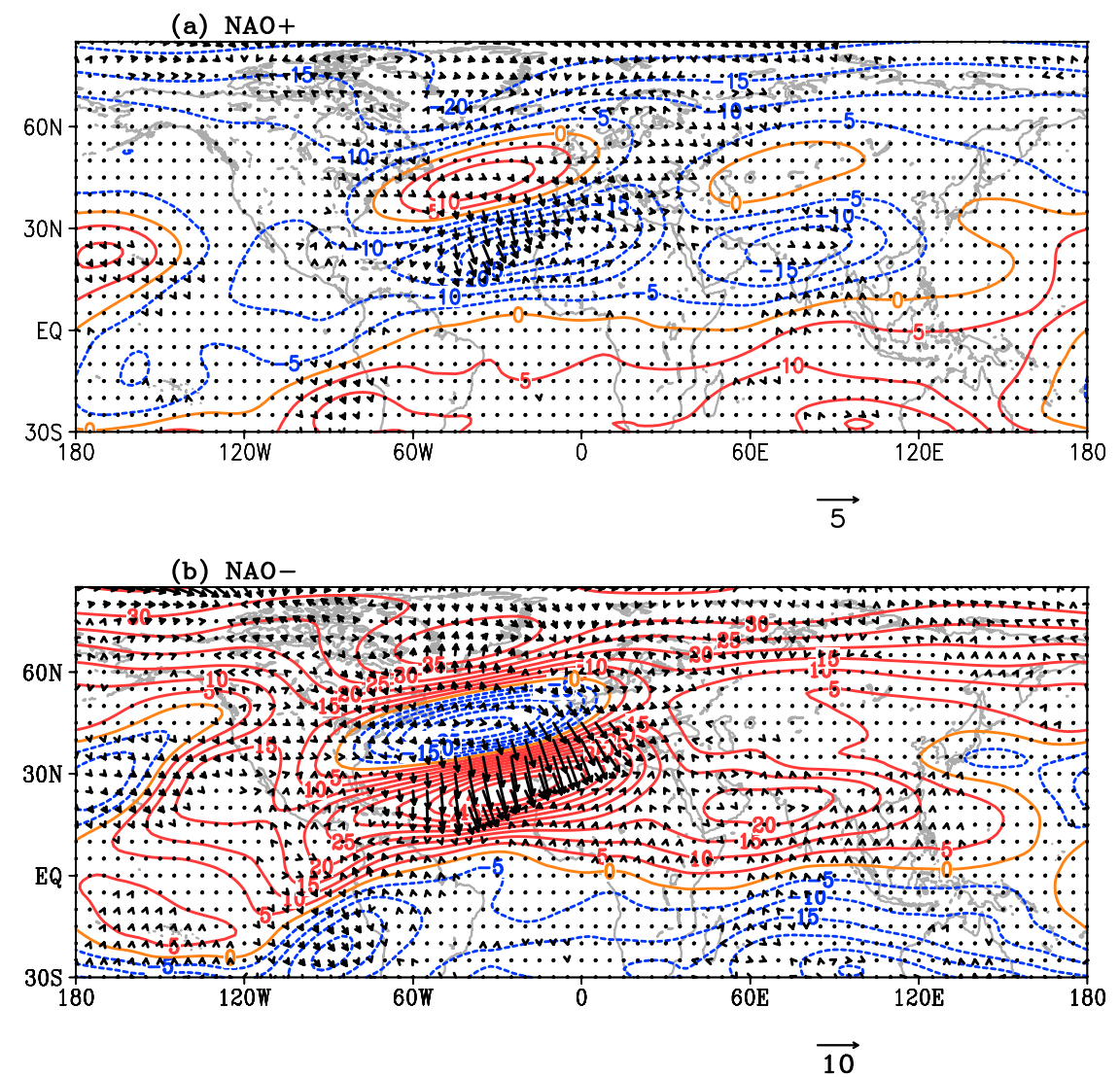

FIG. 13. The 200-hPa streamfunction anomaly (contours) and $\mathbf{W}$ vector in the period of 21 to 30 days following (a) positive and (b) negative NAO events. Positive and negative values of streamfunction anomaly are plotted in red and blue contours, respectively. The contour interval is $5 \times 10^{5} \mathrm{~m}^{2} \mathrm{~s}^{-1}$. Scaling for the arrow is indicated at the bottom. Wave activity flux with magnitude smaller than $0.2 \mathrm{~m}^{2} \mathrm{~s}^{-2}$ is represented by a dot.

Figure 13 suggests wave propagation from the extratropics to the tropics. We use the wave activity flux to diagnose the wave propagation. As defined in Takaya and Nakamura (2001), the wave activity flux vector ( $\mathbf{W}$ vector) is based on the conservation of wave activity pseudomomentum for quasigeostrophic eddies on a zonally varying basic flow and points in the direction of the group velocity. The horizontal component of the $\mathbf{W}$ vector is formulated as

$$
\mathbf{W}=\frac{1}{2|\mathbf{U}|}\left[\begin{array}{c}
U\left(\psi_{x}^{2}-\psi \psi_{x x}\right)+V\left(\psi_{x} \psi_{y}-\psi \psi_{x y}\right) \\
U\left(\psi_{x} \psi_{y}-\psi \psi_{x y}\right)+V\left(\psi_{y}^{2}-\psi \psi_{y y}\right)
\end{array}\right],
$$

where $\psi$ is the streamfunction perturbation and the subscripts represent partial derivatives; $\mathbf{U}=(U, V)$ is the twodimensional time mean flow. Here the $\mathbf{W}$ vector (shown in vectors in Fig. 13) is calculated based on the composite 200-hPa streamfunction anomaly and the observed boreal wintertime mean flow. It should be noted that this wave activity flux is based on quasigeostrophic assumption thus cautions should be exercised for its explanation near the equator. As is seen, 21-30 days after a positive NAO, strong southward wave activity flux appears in the subtropical North Atlantic, originating from the positive $200-\mathrm{hPa}$ streamfunction anomaly center in the midlatitude North Atlantic and converging in the tropics (Fig. 13a). This wave activity flux into the tropics likely acts as an extratropical forcing on the tropics. As a result, a tropical Kelvin wave would develop to the east with anomalous westerlies over the Indian Ocean where the mean flow is dominated by easterlies. The $\mathbf{W}$ vectors following negative NAO (Fig. 13b) are very similar. However, the negative NAO leads to a stronger southward wave activity that propagates farther into low latitudes than the positive NAO, leading to a stronger influence on the MJO, which may explain the MJO skill difference as shown in Fig. 10. A possible explanation for this asymmetry is an equatorward displacement of the critical line (i.e., negative NAO produces westerly anomalies in low latitudes; Fig. 12b), thus moving the zero wind line farther toward the equator.

The tropical response to extratropical forcing has been investigated in several previous studies (e.g., Zhang and Webster 1992; Zhang 1993; Hoskins and Yang 2000). The response was found to be sensitive to the background flow in the tropics. As a response to extratropical forcing, equatorial Kelvin waves can 
be generated in the region of easterly mean flow. In a numerical model experiment with specific extratropical forcing mimicking an extreme positive NAO, Lin et al. (2007) were able to simulate westerly flow response over the tropical Indian Ocean similar to a Kelvin wave.

\section{Summary}

In this study, based on the reforecast data of 11 models of the WWRP/WCRP S2S project, the influence of the NAO prediction of the MJO is investigated. It is found that most models are able to reproduce the MJO phase change following the occurrence of positive and negative NAO events. About three weeks after a positive NAO, there is increased probability of MJO phase 7, while about three weeks following a negative NAO, MJO phase 3 is more likely to occur. This lagged connection of the MJO with the NAO is associated with changes in the 200-hPa zonal wind over the tropical Indian Ocean, where at around day 20, after being initialized with a positive (negative) NAO, there is a dramatic increase of westerly (easterly) wind anomaly near the equator. Most models can predict this 200-hPa zonal wind change. Corresponding to the upper westerly (easterly) wind anomaly over the tropical Indian Ocean following a positive (negative) NAO, the convective activity in the Indian Ocean is suppressed (enhanced), which leads to MJO phase 7 (phase 3).

The MJO prediction skill is found to be dependent on the amplitude of the NAO. In most models, forecasts initialized with a strong NAO have a better MJO prediction skill than those starting from a weak NAO. The skill difference, however, is not apparent for lead times shorter than 15 days, consistent with the lagged influence of the NAO on the MJO. The NAO influences the MJO prediction skill not only as measured by the RMM index, but also for the U200, U850, and OLR components. For all these components, the forecast skill is improved when initialized with a strong NAO. When the general prediction skill, which is measured as the anomaly correlation between forecasts and the observation at each grid point and averaged in the Indian Ocean and western Pacific region, is considered, the prediction skill of U200 is more sensitive to the NAO amplitude than U850 and OLR.

The NAO phase also has substantial impact on the MJO prediction skill. For most models the forecasts starting from a negative NAO produce a more skillful MJO prediction than those from a positive NAO. Models that have MJO prediction skill sensitive to the NAO amplitude tend to also have skill sensitive to the NAO phase. The initial 200-hPa geopotential height and zonal wind anomalies in the North Atlantic are stronger corresponding to a negative NAO than positive NAO, which leads to a stronger wave activity flux into the tropics.

The results have important implications to improved understanding of the MJO and its forecasts, as well as to subseasonal predictions. To improve MJO simulation and prediction, it is important for numerical models to better represent the connection between the NAO and MJO.

The dynamical process for the lagged NAO-MJO connection is not well understood. One possible explanation is that following an NAO event, which has a dipole Z200 anomaly structure in the Greenland and midlatitude North Atlantic regions, there is a slow southward propagation of energy, so that with time the amplitude of the Greenland anomaly center is reduced and a subtropical center develops and enhances. After about 2-3 weeks, wave activity flux converges in the subtropical North Atlantic, causing a local zonal wind acceleration that acts as a forcing on the tropics. As a result, an equatorial Kelvin wave is excited to the east in the region with an easterly mean flow over the tropical Indian Ocean, leading to strong zonal wind anomalies, thereby influencing the MJO. However, questions related to the detail of this process, what controls the southward wave energy propagation, and how the extratropical forcing excites the tropical Kelvin remain unclear. Further observational, numerical modeling, and theoretical studies are needed to fully understand the influence of the NAO on the MJO.

Acknowledgments. This work is based on S2S data. S2S is a joint initiative of the World Weather Research Programme (WWRP) and the World Climate Research Programme (WCRP). The S2S database is hosted at ECMWF as an extension of the TIGGE database. We thank Dr. Steve Woolnough and two anonymous reviewers for their valuable comments and suggestions that helped improve the paper.

\section{REFERENCES}

Adames, Á. F., and D. Kim, 2016: The MJO as a dispersive, convectively coupled moisture wave: Theory and observations. J. Atmos. Sci., 73, 913-941, https://doi.org/10.1175/JAS-D-15-0170.1.

Barnston, A. G., and R. E. Livezey, 1987: Classification, seasonality and persistence of low-frequency atmospheric circulation patterns. Mon. Wea. Rev., 115, 1083-1126, https://doi.org/ 10.1175/1520-0493(1987)115<1083:CSAPOL>2.0.CO;2.

Bechtold, P., M. Koehler, T. Jung, P. Doblas-Reyes, M. Leutbecher, M. Rodwell, and F. Vitart, 2008: Advances in simulating atmospheric variability with the ECMWF model: From synoptic to decadal time-scales. Quart. J. Roy. Meteor. Soc., 134, 1337-1351, https://doi.org/10.1002/qj.289.

Cassou, C., 2008: Intraseasonal interaction between the MaddenJulian Oscillation and the North Atlantic Oscillation. Nature, 455, 523-527, https://doi.org/10.1038/nature07286.

Côté, J., S. Gravel, A. Méthot, A. Patoine, M. Roch, and A. Staniforth, 1998: The operational CMC-MRB Global Environmental Multiscale (GEM) model. Part I: Design considerations and formulation. Mon. Wea. Rev., 126, 1373-1395, https://doi.org/10.1175/1520-0493(1998)126<1373: TOCMGE $>2.0 . \mathrm{CO} ; 2$.

Dee, D. P., and Coauthors, 2011: The ERA-Interim reanalysis: Configuration and performance of the data assimilation system. Quart. J. Roy. Meteor. Soc., 137, 553-597, https://doi.org/ 10.1002/qj.828.

Feng, P.-N., H. Lin, J. Derome, and T. Merlis, 2021: Forecast skill of the $\mathrm{NAO}$ in the subseasonal-to-seasonal prediction models. J. Climate, 34, 4757-4769, https://doi.org/10.1175/JCLI-D-20-0430.1.

Ferranti, L., S. Corti, and M. Janousek, 2015: Flow-dependent verification of the ECMWF ensemble over the Euro-Atlantic sector. Quart. J. Roy. Meteor. Soc., 141, 916-924, https:// doi.org/10.1002/qj.2411.

Frederiksen, J. S., and H. Lin, 2013: Tropical-extratropical interactions of intraseasonal oscillations. J. Atmos. Sci., 70, 31803197, https://doi.org/10.1175/JAS-D-12-0302.1. 
Fuchs, Ž., and D. J. Raymond, 2017: A simple model of intraseasonal oscillations. J. Adv. Model. Earth Syst., 9, 1195-1211, https://doi.org/10.1002/2017MS000963.

Gottschalck, J., and Coauthors, 2010: A framework for assessing operational Madden-Julian oscillation forecasts: A CLIVAR MJO Working Group project. Bull. Amer. Meteor. Soc., 91, 1247-1258, https://doi.org/10.1175/2010BAMS2816.1.

Hall, N. M., S. Thibault, and P. Marchesiello, 2017: Impact of the observed extratropics on climatological simulation of the MJO in a tropical channel model. Climate Dyn., 48, 2541-2555, https://doi.org/10.1007/s00382-016-3221-5.

Hendon, H. H., 2000: Impact of air-sea coupling on the MaddenJulian oscillation in a general circulation model. J. Atmos. Sci., 57, 3939-3952, https://doi.org/10.1175/1520-0469(2001) 058<3939:IOASCO > 2.0.CO;2.

—_, and M. L. Salby, 1994: The life cycle of the Madden-Julian oscillation. J. Atmos. Sci., 51, 2225-2237, https://doi.org/ 10.1175/1520-0469(1994)051<2225:TLCOTM>2.0.CO;2.

Hirons, L. C., P. Inness, F. Vitart, and P. Bechtold, 2013: Understanding advances in the simulation of intraseasonal variability in the ECMWF model. Part I: The representation of the MJO. Quart. J. Roy. Meteor. Soc., 139, 1417-1426, https://doi.org/10.1002/qj.2060.

Hoskins, B. J., and G.-Y. Yang, 2000: The equatorial response to higher-latitude forcing. J. Atmos. Sci., 57, 1197-1213, https://doi.org/10.1175/1520-0469(2000)057<1197:TERTHL> 2.0.CO;2.

Hurrell, J. W., Y. Kushnir, M. Visbeck, and G. Ottersen, 2003: An overview of the North Atlantic Oscillation. The North Atlantic Oscillation: Climatic Significance and Environmental Impact. Geophys. Monogr., Vol. 134, Amer. Geophys. Union, 1-35.

Jiang, X., and Coauthors, 2020: Fifty years of research on the Madden-Julian Oscillation: Recent progress, challenges, and perspectives. J. Geophys. Res. Atmos. 125, e2019JD030911, https://doi.org/10.1029/2019JD030911.

Johansson, A., 2007: Prediction skill of the NAO and PNA from daily to seasonal time scales. J. Climate, 20, 1957-1975, https:// doi.org/10.1175/JCLI4072.1.

Khairoutdinov, M. F., and K. Emanuel, 2018: Intraseasonal variability in a cloud-permitting near-global equatorial aquaplanet model. J. Atmos. Sci., 75, 4337-4355, https://doi.org/ 10.1175/JAS-D-18-0152.1.

Kim, H.-M., P. J. Webster, V. E. Toma, and D. Kim, 2014: Predictability and prediction skill of the MJO in two operational forecasting systems. J. Climate, 27, 5364-5378, https:// doi.org/10.1175/JCLI-D-13-00480.1.

Liebmann, B., and D. L. Hartmann, 1984: An observational study of tropical-midlatitude interaction on intraseasonal time scales during winter. J. Atmos. Sci., 41, 3333-3350, https://doi.org/ 10.1175/1520-0469(1984)041<3333:AOSOTI>2.0.CO;2.

— outgoing longwave radiation dataset. Bull. Amer. Meteor. Soc., 77, 1275-1277, https://doi.org/10.1175/1520-0477-77.6.1274.

Lim, Y., S.-W. Son, and D. Kim, 2018: MJO prediction skill of the subseasonal-to-seasonal prediction models. J. Climate, 31, 4075-4094, https://doi.org/10.1175/JCLI-D-17-0545.1.

— - _ A. G. Marshall, H. H. Hendon, and K.-H. Seo, 2019: Influence of the QBO on MJO prediction skill in the subseasonal-to-seasonal prediction models. Climate Dyn., 53, 1681-1695, https://doi.org/10.1007/s00382-019-04719-y.

Lin, H., 2020: Subseasonal forecast skill over the northern polar region in boreal winter. J. Climate, 33, 1935-1951, https:// doi.org/10.1175/JCLI-D-19-0408.1.
— , and G. Brunet, 2011: Impact of the North Atlantic Oscillation on the forecast skill of the Madden-Julian Oscillation. Geophys. Res. Lett., 38, L02802, https://doi.org/10.1029/2010GL046131.

— and — 2018: Extratropical response to the MJO: Nonlinearity and sensitivity to initial state. J. Atmos. Sci., 75, 219-234, https:// doi.org/10.1175/JAS-D-17-0189.1.

$\longrightarrow,-$, and J. Derome, 2007: Intraseasonal variability in a dry atmospheric model. J. Atmos. Sci., 64, 2422-2441, https:// doi.org/10.1175/JAS3955.1.

- — , and _ 2008: Forecast skill of the Madden-Julian oscillation in two Canadian atmospheric models. Mon. Wea. Rev., 136, 4130-4149, https://doi.org/10.1175/2008MWR2459.1.

_ —_, and ——, 2009: An observed connection between the North Atlantic Oscillation and the Madden-Julian oscillation. J. Climate, 22, 364-380, https://doi.org/10.1175/ 2008JCLI2515.1.

- - , and R. Mo, 2010a: Impact of the Madden-Julian oscillation on wintertime precipitation in Canada. Mon. Wea. Rev., 138, 3822-3839, https://doi.org/10.1175/2010MWR3363.1.

,-- , and J. S. Fontecilla, 2010b: Impact of the MaddenJulian oscillation on the intraseasonal forecast skill of the North Atlantic Oscillation. Geophys. Res. Lett., 37, L19803, https://doi.org/10.1029/2010GL044315.

—, J. Frederiksen, D. Straus, and C. Stan, 2019: Tropicalextratropical interactions and teleconnections. Sub-Seasonal to Seasonal Prediction: The Gap Between Weather and Climate Forecasting, A. W. Robertson and F. Vitart, Eds., Elsevier, 143-164.

Madden, R. A., and P. R. Julian, 1971: Description of a 40-50 day oscillation in the zonal wind in the tropical Pacific. J. Atmos. Sci., 28, 702-708, https://doi.org/10.1175/1520-0469(1971) $028<0702$ :DOADOI $>2.0$.CO;2.

—_, and ——, 1994: Observations of the 40-50-day tropical oscillation-A review. Mon. Wea. Rev., 122, 814-837, https:// doi.org/10.1175/1520-0493(1994)122<0814:OOTDTO>2.0.CO;2.

Marshall, A. G., H. H. Hendon, S.-W. Son, and Y. Lim, 2017: Impact of the quasi-biennial oscillation on predictability of the Madden-Julian oscillation. Climate Dyn., 49, 1365-1377, https://doi.org/10.1007/s00382-016-3392-0.

Matthews, A. J., and G. N. Kiladis, 1999: The tropical-extratropical interaction between high-frequency transients and the MaddenJulian oscillation. Mon. Wea. Rev., 127, 661-677, https://doi.org/ 10.1175/1520-0493(1999)127<0661:TTEIBH > 2.0.CO;2.

Murphy, A. H., and E. S. Epstein, 1989: Skill scores and correlation coefficients in model verification. Mon. Wea. Rev., 117, 572-582, https://doi.org/10.1175/1520-0493(1989)117<0572: SSACCI $>2.0 . \mathrm{CO} ; 2$.

National Academies of Sciences, Engineering, and Medicine, 2016: Next Generation Earth System Prediction: Strategies for Subseasonal to Seasonal Forecasts. National Academies Press, 350 pp., https://doi.org/10.17226/21873.

Neena, J. M., J. Y. Lee, D. Waliser, B. Wang, and X. Jiang, 2014: Predictability of the Madden-Julian oscillation in the Intraseasonal Variability Hindcast Experiment (ISVHE). J. Climate, 27, 45314543, https://doi.org/10.1175/JCLI-D-13-00624.1.

Pegion, K., and Coauthors, 2019: The Subseasonal Experiment (SubX): A multimodel subseasonal prediction experiment. Bull. Amer. Meteor. Soc., 100, 2043-2060, https://doi.org/ 10.1175/BAMS-D-18-0270.1.

Rashid, H. A., H. H. Hendon, M. C. Wheeler, and O. Alves, 2011: Prediction of the Madden-Julian oscillation with the POAMA dynamical prediction system. Climate Dyn., 36, 649-661, https://doi.org/10.1007/s00382-010-0754-x 
Ray, P., and C. Zhang, 2010: A case study of the mechanisms of extratropical influence on the initiation of the Madden-Julian oscillation. J. Atmos. Sci., 67, 515-528, https://doi.org/10.1175/ 2009JAS3059.1.

Raymond, D. J., 2001: A new model of the Madden-Julian oscillation. J. Atmos. Sci., 58, 2807-2819, https://doi.org/10.1175/ 1520-0469(2001)058<2807:ANMOTM > 2.0.CO;2.

Seo, H., A. C. Subramanian, A. J. Miller, and N. R. Cavanaugh, 2014: Coupled impacts of the diurnal cycle of sea surface temperature on the Madden-Julian oscillation. J. Climate, 27, 8422-8443, https://doi.org/10.1175/JCLI-D-14-00141.1.

Shao, X., J. Song, and S. Li, 2019: The lagged connection of the positive NAO with the MJO phase 3 in a simplified atmospheric model. Theor. Appl. Climatol., 135, 1091-1103, https:// doi.org/10.1007/s00704-018-2425-5.

Sobel, A., and E. Maloney, 2012: An idealized semi-empirical framework for modeling the Madden-Julian oscillation. J. Atmos. Sci., 69, 1691-1705, https://doi.org/10.1175/JAS-D11-0118.1.

- , and -2013 : Moisture modes and the eastward propagation of the MJO. J. Atmos. Sci., 70, 187-192, https://doi.org/ 10.1175/JAS-D-12-0189.1.

Son, S.-W., Y. Lim, C. Yoo, H. H. Hendon, and J. Kim, 2017: Stratospheric control of the Madden-Julian oscillation. J. Climate, 30, 1909-1922, https://doi.org/10.1175/JCLI-D16-0620.1.

Sperber, K. R., 2003: Propagation and the vertical structure of the Madden-Julian oscillation. Mon. Wea. Rev., 131, 3018-3037, https:// doi.org/10.1175/1520-0493(2003)131<3018:PATVSO>2.0.CO;2.

Stan, C., D. Straus, J. Frederiksen, H. Lin, E. Maloney, and C. Schumacher, 2017: Review of tropical-extratropical teleconnections on intraseasonal time scales. Rev. Geophys., $\mathbf{5 5}$, 902-937, https://doi.org/10.1002/2016RG000538.

Straub, K. H., 2013: MJO initiation in the real-time multivariate MJO index. J. Climate, 26, 1130-1151, https://doi.org/10.1175/ JCLI-D-12-00074.1.

Straus, D. M., E. Swenson, and C.-L. Lappen, 2015: The MJO cycle forcing of the North Atlantic circulation: Intervention experiments with the Community Earth System Model. J. Atmos. Sci., 72, 660-681, https://doi.org/10.1175/JAS-D-14-0145.1.

Takaya, K., and H. Nakamura, 2001: A formulation of a phaseindependent wave-activity flux for stationary and migratory quasigeostrophic eddies on a zonally varying basic flow. J. Atmos. Sci., 58, 608-627, https://doi.org/10.1175/15200469(2001)058<0608:AFOAPI > 2.0.CO;2.

Tseng, K. C., E. A. Barnes, and E. D. Maloney, 2018: Prediction of the midlatitude response to strong Madden-Julian oscillation events on S2S time scales. Geophys. Res. Lett., 45, 463-470, https://doi.org/10.1002/2017GL075734.

Ventrice, M. J., M. C. Wheeler, H. H. Hendon, C. J. Schreck, C. D. Thorncroft, and G. N. Kiladis, 2013: A modified multivariate Madden-Julian oscillation index using velocity potential. Mon. Wea. Rev., 141, 4197-4210, https://doi.org/10.1175/MWRD-12-00327.1.

Vitart, F., 2017: Madden-Julian oscillation prediction and teleconnections in the S2S database. Quart. J. Roy. Meteor. Soc., 143, 2210-2220, https://doi.org/10.1002/qj.3079.

— , and T. Jung, 2010: Impact of the Northern Hemisphere extratropics on the skill in predicting the Madden Julian
Oscillation. Geophys. Res. Lett., 37, L23805, https://doi.org/ 10.1029/2010GL045465.

- and A. W. Robertson, 2018: The sub-seasonal to seasonal prediction project (S2S) and the prediction of extreme events. npj Climate Atmos. Sci., 1, 3, https://doi.org/10.1038/s41612018-0013-0.

— prediction project database. Bull. Amer. Meteor. Soc., 98, 163173, https://doi.org/10.1175/BAMS-D-16-0017.1.

Waliser, D. E., 2012: Predictability and forecasting. Intraseasonal Variability in the Atmosphere-Ocean Climate System, W. K. M. Lau and D. E. Waliser, Eds., Springer, 433-476, Chapter 12.

Wallace, J. M., and D. S. Gutzler, 1981: Teleconnections in the geopotential height field during the Northern Hemisphere winter. Mon. Wea. Rev., 109, 784-812, https://doi.org/10.1175/ 1520-0493(1981)109<0784:TITGHF>2.0.CO;2.

Wang, W., M.-P. Hung, S. J. Weaver, A. Kumar, and X. Fu, 2014: MJO prediction in the NCEP Climate Forecast System version 2. Climate Dyn., 42, 2509-2520, https://doi.org/10.1007/ s00382-013-1806-9.

Webster, P. J., and J. R. Holton, 1982: Cross-equatorial response to middle-latitude forcing in a zonally varying basic state. J. Atmos. Sci., 39, 722-733, https://doi.org/10.1175/15200469(1982)039<0722:CERTML>2.0.CO;2.

Wheeler, M., and H. H. Hendon, 2004: An all-season real-time multivariate MJO index: Development of an index for monitoring and prediction. Mon. Wea. Rev., 132, 1917-1932, https://doi.org/ 10.1175/1520-0493(2004)132<1917:AARMMI > 2.0.CO;2.

Woolnough, S. J., F. Vitart, and M. A. Balmaseda, 2007: The role of the ocean in the Madden-Julian oscillation: Implications for MJO prediction. Quart. J. Roy. Meteor. Soc., 133, 117-128, https://doi.org/10.1002/qj.4.

Xiang, B., M. Zhao, X. Jiang, S.-J. Lin, T. Li, X. Fu, and G. Vecchi, 2015: The 3-4-week MJO prediction skill in a GFDL coupled model. J. Climate, 28, 5351-5364, https://doi.org/10.1175/JCLID-15-0102.1.

Yadav, P., D. M. Straus, and E. T. Swenson, 2019: The EuroAtlantic circulation response to the Madden-Julian oscillation cycle of tropical heating: Coupled GCM intervention experiments. Atmos.-Ocean, 57, 161-181, https://doi.org/10.1080/ 07055900.2019 .1626214$.

Yang, D., Á. F. Adames-Corraliza, B. Khouider, B. Wang, and C. Zhang, 2020: A review of MJO theories. The Multiscale Global Monsoon System. C.-P. Chang et al., Eds.,World Scientific, 233247, https://doi.org/10.1142/9789811216602_0019.

Zhang, C., 1993: Laterally forced equatorial perturbations in a linear model. Part II: Mobile forcing. J. Atmos. Sci., 50, 807-821, https:// doi.org/10.1175/1520-0469(1993)050<0807:LFEPIA > 2.0.CO;2.

_ , 2005: Madden-Julian Oscillation. Rev. Geophys., 43, RG2003, https://doi.org/10.1029/2004RG000158.

_ turbations in a linear model. Part I: Stationary transient forcing. J. Atmos. Sci., 49, 585-607, https://doi.org/10.1175/ 1520-0469(1992)049<0585:LFEPIA > 2.0.CO;2.

_- Á. F. Adames, B. Khouider, B. Wang, and D. Yang, 2020: Four theories of the Madden-Julian Oscillation. Rev. Geophys., 58, e2019RG000685, https://doi.org/10.1029/ 2019RG000685. 